\title{
Experimental and computational studies of poly-L-lactic acid for cardiovascular applications: recent progress
}

\author{
Raasti Naseem, Liguo Zhao ${ }^{*}$, Yang Liu and Vadim V. Silberschmidt
}

\begin{abstract}
Stents are commonly used in medical procedures to alleviate the symptoms of coronary heart disease, a prevalent modern society disease. These structures are employed to maintain vessel patency and restore blood flow. Traditionally stents are made of metals such as stainless steel or cobalt chromium; however, these scaffolds have known disadvantages. An emergence of transient scaffolds is gaining popularity, with the structure engaged for a required period whilst healing of the diseased arterial wall occurs. Polymers dominate a medical device sector, with incorporation in sutures, scaffolds and screws. Thanks to their good mechanical and biological properties and their ability to degrade naturally. Polylactic acid is an extremely versatile polymer, with its properties easily tailored to applications. Its dominance in the stenting field increases continually, with the first polymer scaffold gaining FDA approval in 2016. Still some challenges with PLLA bioresorbable materials remain, especially with regard to understanding their mechanical response, assessment of its changes with degradation and comparison of their performance with that of metallic drug-eluting stent. Currently, there is still a lack of works on evaluating both the pre-degradation properties and degradation performance of these scaffolds. Additionally, there are no established material models incorporating non-linear viscoelastic behaviour of PLLA and its evolution with in-service degradation. Assessing these features through experimental analysis accompanied by analytical and numerical studies will provide powerful tools for design and optimisation of these structures endorsing their broader use in stenting. This overview assesses the recent studies investigating mechanical and computational performance of poly(l-lactic) acid and its use in stenting applications.
\end{abstract}

Keywords: Biodegradable, Polymer scaffolds, Degradation, Mechanical properties, PLLA

\section{Introduction}

Atherosclerosis, a type of coronary heart disease (CHD), is a process, in which a build-up of fatty material (atheroma) occurs inside arterial walls (Fig. 1). This leads to narrowing of the artery, causing severe ailments (i.e., heart attack or angina) and a high rate of fatality (NHS 2014). CHD is a leading cause of mortality worldwide and contributes to the death of more than one in seven men and almost one in ten women in the United Kingdom, making it the UK's biggest killer (British Heart Foundation 2015).

Coronary artery bypass grafting (CABG) or percutaneous coronary intervention (PCI) are generally used to treat patients with a coronary artery disease. CABG is a

\footnotetext{
* Correspondence: L.Zhao@lboro.ac.uk

Wolfson School of Mechanical, Electrical and Manufacturing Engineering, Loughborough University, Loughborough LE11 3TU, UK
}

procedure, where a healthy artery section is removed from another site in the body and grafted in order to bypass the site of occlusion, ultimately creating a new path for continuous blood flow (NIH 2012). In contrast, PCI is a nonsurgical procedure, with the occluded artery section widened through inflation of a balloon mounted onto a catheter (Fig. 2). Balloon angioplasty, pioneered by Andres Grüntzig in 1977, was the first procedure by which medical professionals were able to intervene non-surgically in order to establish coronary revascularization (Gruntzig 1978; Simard et al. 2014; Kočka et al. 2015). This method was found to be effective in initiating patency to a narrowed or blocked artery; however, severe life-threatening risks were also associated with it as a result of a high threat of restenosis (occurrence of vessel blockage triggered by arterial remodelling and intima hyperplasia) due 


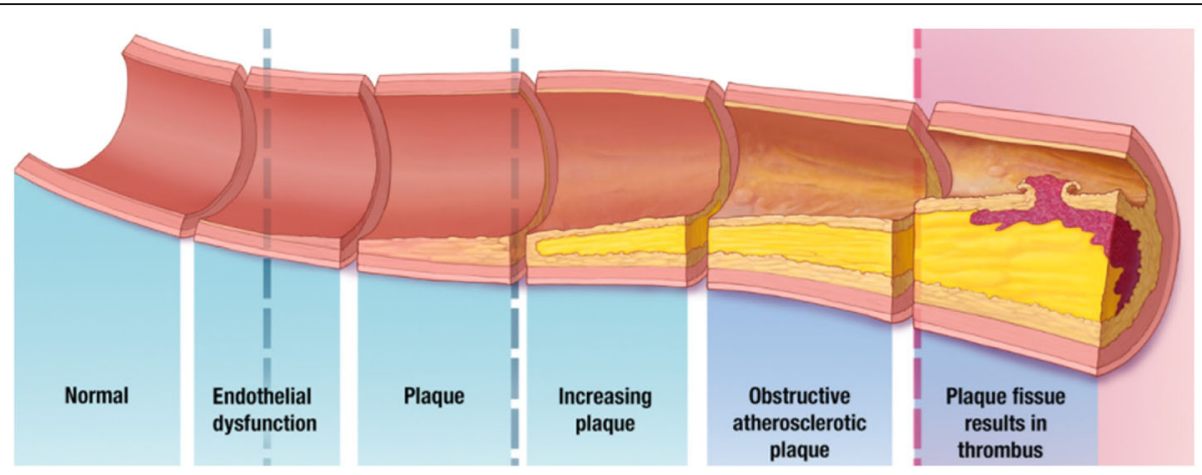

Fig. 1 Atherosclerosis sequence (Widmer et al. 2016)

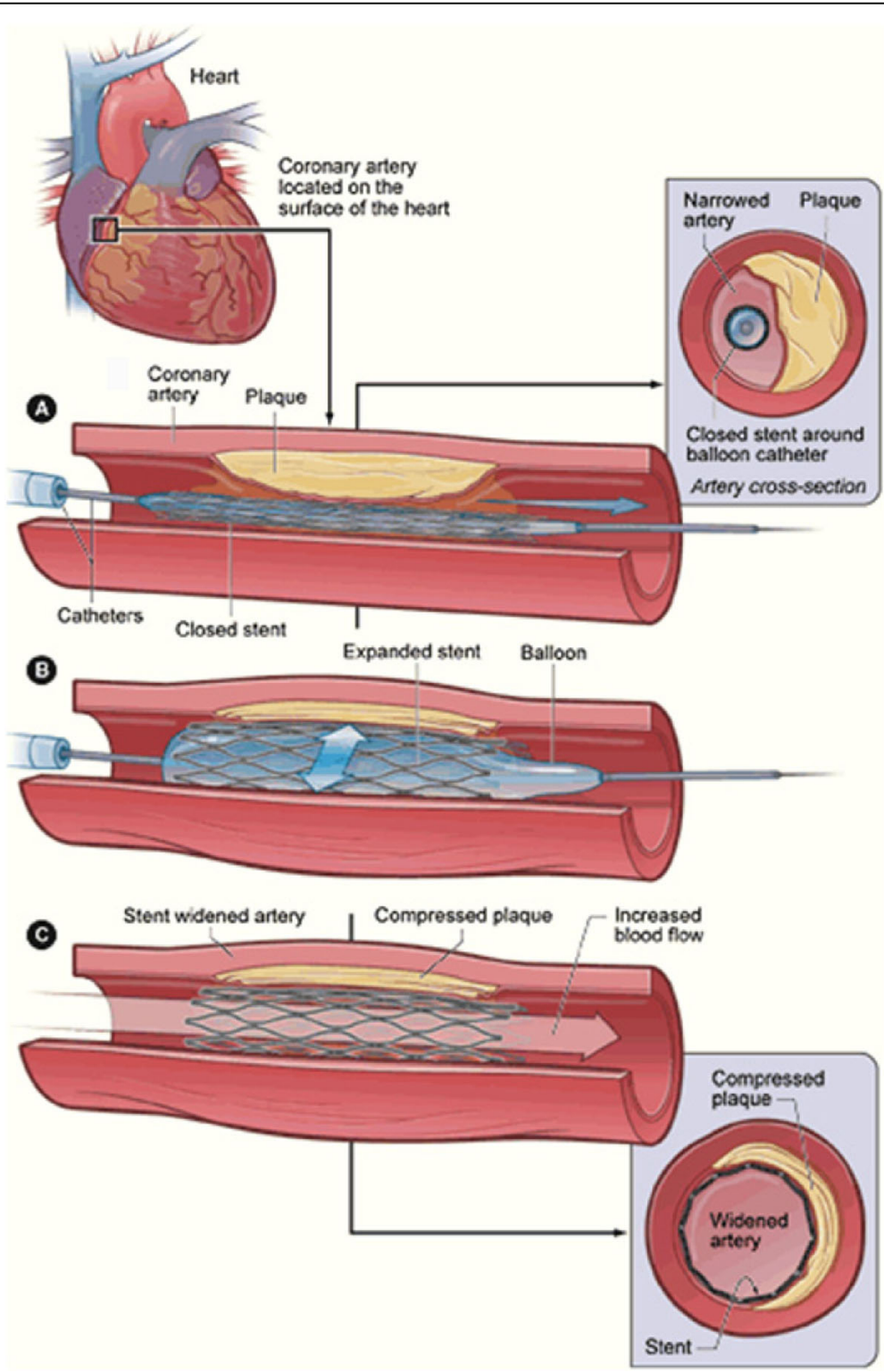

Fig. $2 \mathrm{PCl}$ procedure illustrating stent implant (Fortier et al. 2014) 
to coronary dissection and arterial recoil (Oberhauser et al. 2009; Serruys et al. 2012; Bourantas et al. 2013; Simard et al. 2014; Kočka et al. 2015).

The development of coronary stents began in the 1980 s as a means to overcome the restenosis issues related to balloon angioplasty (Hoffmann and Mintz 2000; Kočka et al. 2015). This scheme is based on the introduction of scaffolding of the artery with balloon inflated metallic stents averting early constrictive remodelling, stabilizing vascular dissections and eliminating arteral recoil. Bare metal stents (BMSs) were introduced to alleviate problems seen with balloon angioplasty, e.g. acute vessel closure caused by dissection, elastic recoil, neointimal proliferation and a late occurrence of constrictive remodelling (Hara et al. 2006; O' Brien et al. 2011; Iqbal et al. 2014; Simard et al. 2014). Generally, the permanent structures were able to maintain a widened lumen and deemed an improvement on balloon angioplasty; however, the occurrences of in-stent restenosis increased with time as a result of neointimal proliferation (Schatz et al. 1991). Although incidences of restenosis declined with BMS implants, vessel narrowing still occurred in 20-30\% of stented lesions (Serruys et al. 1994). Bare metal stents also pose a risk to surgical revasculariazation and impaired non-invasive imaging techniques, such as multi-slice computed tomography, used to image an implant in vivo (Agrawal et al. 1992; Serruys et al. 2009; Oberhauser et al. 2009; Nishio et al. 2012). Permanent metallic stents also have potential to jail side branches, prevent expansive positive remodelling and eliminate reactive vasomotion (Ormiston et al. 2008). The risk of complication is even more critical due to fatigue loading, experienced by a stented artery and caused by a compliance disparity between the metal implant and the arterial wall (Nishio et al. 2012). In order to overcome these limitations, research was directed at new types of stents.

In 2002, the third generation of stents (see Table 1), drug eluting stent (DES), was introduced. These stents were based on permanent scaffolds, i.e., a metallic backbone with a polymeric drug-delivery coating (Kočka et al. 2015). The main objective of DES was to reduce a vascular inflammatory response and cell proliferation in order to eliminate an excessive hyperplastic healing response observed in BMSs to diminish a chance of ISR occurance (Abizaid and Costa Jr., 2010; Simard et al. 2014; Verheye et al. 2014). Pharmacologic agents commonly used in

Table 1 Stent evolution

\begin{tabular}{ll}
\hline 1st Generation (1977) & •Balloon Angioplasty \\
2nd Generation (1980's) & •Bare metal stents \\
3rd Generation (2002) & -Drug-eluting stents (permanent) \\
4th Generation (2016) & -Drug-eluting stents (bioresorbable) \\
\hline
\end{tabular}

DESs are usually cytotoxic, antiproliferative and/or immunosuppressive to reduce a growth of smooth muscle cells growth post coronary intervention (Simard et al. 2014). Studies showed that drug-eluting stents, in comparison to BMSs, minimize smooth-muscle proliferation (neointimal hyperplasia), reduced restenosis and decreased the rates of target lesion revascularization by $50-70 \%$ (Serruys et al. 2006; Kočka et al. 2015). Unfortunately, safety problems arose with the use of first-generation DESs particularly, with respect to late stent thrombosis that delayed healing (Gada et al. 2013). This is associated with antiprolifertive drugs used to coat the stent backbone, delaying endothelialisation of the implanted stent (Iakovou et al. 2005). Additionally, polymers used to load drugs onto the stent surface, could initiate an inflammatory response contributing to a prothrombotic environment (Kristensen and Grove 2007). To address these issues, second-generation DESs were developed, with thinner struts, enhanced biocompatibility and biodegradable polymers for the stent backbone. This greatly improved the safety profile of DESs however, they were still permanent implants. A new generation of stents, bioresorbable scaffolds, are under research and development, with a focus on full biodegradability.

Absorbable cardiovascular scaffolds deliver temporary support to vasculature; they are implanted with the intention of degradation and resorption by the body's metabolic pathways, the key notion being the transient requirement for vessel scaffolding (Oberhauser et al. 2009). Scaffolds play a role in vascular restoration therapy, involving an endothelial function and vasomotion, where endothelium dysfunction was shown to be reversible (Celermajer 1997; Oberhauser et al. 2009). In comparison to permanent stenting (BMSs \& DESs), bioresorbable stents enhance arterial recovery, allowing the vessel to react normally to pulsatile flow, positively remodel and respond in a normal manner to biochemical factors released by the endothelium (Ormiston et al. 2007). Functional endothelial coverage can also contribute towards a diminished risk of stent thrombosis and meet a requirement for long-term use of antiplatelet therapy (Ormiston and Serruys 2009). Restoration of mechano-transduction, adaptive shear stress, late luminal gain (as opposed to late luminal loss as seen with permanent stents) and late expansive remodelling are major enhancements achieved with BRSs (Serruys et al. 2012; Iqbal et al. 2014). The predominant aspect which distinguishes bioabsorbable stents from BMSs and DESs, is a capacity to restore natural vascular response in the vessel. Together with a significant reduction in restenosis and late stent thrombosis as well as a potential for re-intervention at the injury site, reduction in dual antiplatelet therapy prescription and improved non-invasive imaging bioabsorbable stents are an extraordinary device, which could change the outcomes of PCI (Oberhauser et al. 2009). Bioresorbable stents also have higher flexibility in comparison to metal 
ones, enabling better tracking when implanting the device into complex anatomies (Bourantas et al. 2013). A comparison of main types of stents is given in Table 2.

The intent of temporary scaffolding of the artery is to provide initial mechanical support, but with elastic recoil, constrictive remodelling and endothelium dysfunction being of concern. Alleviation of these matters make permanent stenting redundant after the vessel has fully recovered (Oberhauser et al. 2009; Simard et al. 2014). It is therefore crucial, in order to achieve successful revascularization at the injury site, that there is a sufficient level of luminal support for the required time frame (Luo et al. 2014). This involves the adjustment of device performance (i.e., duration of radial scaffolding and structural continuity), with the consideration of physiological behaviours (e.g. lumen stabilization and cellular matrix deposition). Bioabsorbable scaffolds are revolutionizing cardiovascular interventions; however their use in clinical procedures is still sparse due to the lack of experimental and computational analysis of their efficiency and suitability. This review assesses the current state of such studies performed in the past 15 years to contribute to accelerated introduction of implants into medical practice. It covers mechanical testing of PLLA material and scaffolds and addresses factors, affecting behaviour of polymer. Computational studies of PLLA scaffolds introduced in more recent years are also noted and discussed.

\section{Review}

\section{Poly (L-lactic) acid used in bioresorbable stenting Material}

PLLA is the material currently used for bioresorbable stents available on the market, due to its high biocompatibility,

Table 2 Comparison of BRS with other angioplasty techniques/ devices (lqbal et al. 2014)

\begin{tabular}{lllll}
\hline & POBA & BMS & DES & BRS \\
\hline Acute occlusion & - & + & + & + \\
Acute recoil & - & + & + & + \\
Acute thrombosis & - & - & - & - \\
Sub-acute thrombosis & \pm & - & - & - \\
Late thrombosis & + & - & - & \pm \\
Very late thrombosis & + & \pm & $-/ \pm$ & $+/ ?$ \\
Neointimal hyperplasia & - & - & + & + \\
Constrictive remodelling & - & + & + & + \\
Adaptive (expansive) remodelling & + & - & - & + \\
Restoration of vasomotion & + & - & - & + \\
Late luminal enlargement & + & - & - & +
\end{tabular}

[POBA - plain old balloon angioplasty; BMS - bare metal stent; DES - drug eluting stent; BRS - bioresorbable scaffold; + - positive/beneficial; - negative/ no effect; \pm - neutral or uncertain effect;? - lack of definitive evidence] No with direct comparison study of four techniques therefore, the table is compiled based on non-comparative data (Iqbal et al. 2014)] reasonable rates of biodegradation and adaptable physical and chemical nature (Li and Vert 2002). Naturally sourced lactic acid undergoes condensation polymerization in order to produce PLLA (Zhang 2015). Poly (L-lactide) is biodegradable, biocompatible, non-toxic, semi-crystalline polyester, which forms a blend of amorphous and crystalline phases upon solidification; the proportion of these fractions is defined by the thermal and deformation history during processing within the PLLA structure (Quynh et al. 2007; Ormiston et al. 2008; Foin et al. 2014). Mechanically, it has a high tensile strength which makes it an ideal material for use in load-bearing applications (Weir et al. 2004), though raw polylactic acid, a glassy polymer, has a moderately low strength and poor elongation at break. Chemical modifications, blending with other polymers and control of polymer chain orientation are amongst methods used to improve polymer's mechanical properties and tailor its resorption rate (Grijpma et al. 2002; Pruitt and Chakravartula 2011; Foin et al. 2014). The radiolucent material is a clinically approved material, and illustrated to be safe in human coronary arteries (Tamai et al. 2000; Ormiston and Serruys 2009; Yang and Fernandez 2015). At room and physiological temperatures, PLLA is in a solid state as it is below the glass-transition temperature $\left(\mathrm{T}_{\mathrm{g}}\right)$. Table 3 illustrates typical properties of PLLA; however these can vary with parameters of manufacturing processes such as annealing temperature, extrusion method and blow moulding (Ormiston et al. 2008; Yang and Fernandez 2015). Variation of its elastic modulus with different manufacturing processes, is presented in Table 4.

\section{Mechanical testing of PLLA for use in cardiovascular interventions}

Due to strict guidelines, which stent manufacturers must adhere to, there is an obligation for them to provide performance evidence for manufactured scaffolds. This, in turn, assists with further development of devices as well as a wider spread of device approval and clinical use. There are various techniques and guidelines, which can be employed to mechanical tests of stents, including threepoint bending (ASTM F2606; ASTM 2014a), radial force testing (ASTM F3067; and a specific set of guidelines for testing of absorbable stents (ASTM F3067)(ASTM 2013).

Table 3 PLLA properties (Röhm and Aldrich; Tamai et al. 2000; Hoffmann and Mintz 2000; Zhang 2015)

\begin{tabular}{ll}
\hline Property & Value \\
\hline Melting temperature $-\mathrm{T}_{\mathrm{m}}\left({ }^{\circ} \mathrm{C}\right)$ & $170-190$ \\
Transition temperature $-\mathrm{T}_{\mathrm{g}}\left({ }^{\circ} \mathrm{C}\right)$ & $50-65$ \\
Tensile strength $(\mathrm{MPa})$ & $50-70$ \\
Crystallinity $(\%)$ & 37 \\
Young's modulus (GPa) & $2.7-16$ \\
Elongation at break (\%) & $30-40$ \\
\hline
\end{tabular}


Table 4 Variation of PLLA elastic modulus with manufacturing method

\begin{tabular}{llll}
\hline Reference & Sample shape & $\begin{array}{l}\text { Manufacture } \\
\text { method }\end{array}$ & $\begin{array}{l}\text { Elastic } \\
\text { modulus (GPa) }\end{array}$ \\
\hline $\begin{array}{l}\text { Weir et al. } \\
\text { (2004) }\end{array}$ & Dog bone & $\begin{array}{l}\text { Compression } \\
\text { moulding }\end{array}$ & 0.62 \\
$\begin{array}{l}\text { Grabow et al. } \\
\text { (2005) }\end{array}$ & Dog bone & Laser cut & 2.85 \\
$\begin{array}{l}\text { Leenslag et al. } \\
\text { (1984) }\end{array}$ & Fibres & $\begin{array}{l}\text { Dry-spinning / } \\
\text { hot-drawing }\end{array}$ & 11.4 \\
\hline
\end{tabular}

The last document detail securement of a vascular stent onto a delivery system, three-point bending of the whole device and a method to measure its intrinsic recoil. However, these methods do not assess evolution of mechanical performance of stents with degradation. It is worthwhile to mention that testing of the bulk material may not provide mechanical data suitable for devices due to changes caused by manufacturing and processing conditions when this bulk material is transformed into a tubular scaffold with fine details at a scale of $100 \mu \mathrm{m}$. According to the literature there are no guidelines for measurements of the mechanical performance of polymeric scaffolds with degradation and analysis of their local mechanical properties (i.e., for varying locations across the scaffold). It is also important to note that in-vitro testing is not representative of the in-vivo environment, though it does allow for more comprehensive data for computational studies. In the subsequent sections, methods used by different research groups to characterize stent performance mechanically by taking into consideration the effect of manufacturing processes on material properties are reviewed. Experimental conditions in-vitro are also discussed, along with degradation behaviour of PLLA.

\section{Effect of processing on mechanical properties}

Agrawal et al. (1992) performed one of the first studies investigating the mechanical properties of PLLA for use in vascular stents, specifically looking at the effects of processing. Elastic and shear moduli for PLLA fibres subjected to higher draw ratios were investigated. Stent cohorts were synthesized from PLLA monofilaments, each with varying draw ratios. The elastic modulus and UTS were found to increase with draw ratios of the monofilaments; however, this caused a decrease in the shear modulus and elongation at break. Such alterations in properties are related to an increased degree of longitudinal molecular orientation caused by drawing. Monofilaments for each draw ratio were then split in three groups; control, annealing at $140{ }^{\circ} \mathrm{C}$ (constrained) and unconstrained annealing at the same temperature. Constrained annealing, with the ends of the monofilaments fixed, gave enhanced elastic and shear moduli compared to the control group. The main outcome of this research was the link between the mechanical properties of the PLLA monofilament and the draw ratio and thermal history. Fambri et al. (1997) corroborated this research by assessing PLLA fibres produced by melt spinning. Processes such as extrusion and hot drawing contributed to the decline in molecular weight of a material. Gupta et al. (Gupta et al. 2007) presented a comprehensive overview of PLLA fibres, including the variety of production methods and the correlation between their structure and properties. With regard to their use in medical applications, e.g. stents, it was noted that tailoring the microstructure enabled modification of mechanical properties of scaffolds. It was stated that due to the limitations of material properties of PLLA (weaker mechanical properties compared with metals used in stents and more brittle nature) polymeric modifications, blending with other polymers and producing micro-/ nano-composites of PLLA could overcome these challenges (Madhavan Nampoothiri et al. 2010).

Grabow et al. (2005) assessed micro-specimens of PLLA to quantify the effect of laser machining and sterilization techniques on mechanical properties, with a comparison made between pure PLLA and PLLA with plasticizer. Dimensions of samples, (although not in the form of cylinder), were adapted to match the strut size of polymer scaffolds. Plasticizer incorporation significantly enhanced the elongation at break of the PLLA polymer, which would enable accumulation of higher maximum strain without strut rupture compared to pure PLLA; however the adverse effect was observed for creep behaviour of the material. Grabow et al. (2005) clearly demonstrated that processing conditions should not be disregarded when selecting a suitable material for stenting applications. Annealing is a secondary process, wherein the material is brought to a certain temperature, kept there for some time and then cooled down to room temperature. The main aims of for annealing include the reduction or removal of residual stresses and strains, dimensional stabilization, reduction or elimination of defects and improvement of physical properties (LeGrand 2011). This process was found to have a significant effect on mechanical properties of PLLA samples where, generally, a higher annealing temperature resulted in a polymer with higher crystallinity and a more ordered crystalline phase (Renouf-Glauser et al. 2005; Welch et al. 2008). This reiterates that material processing conditions affect significantly mechanical properties (Perego et al. 1996; Sarasua et al. 2005).

A review by Bergstrom and Hayman (2016) concluded that PLLA, like other bioresorbable polymers, demonstrated highly non-linear mechanical behaviour. This was attributable to strong effects of temperature, molecular weight, molecular orientation, crystallinity and physical ageing characteristics on properties, which 
could be tailored through material processing. The paper highlighted a link between the Young's modulus and elongation to failure at room temperature for a range of PLLA materials with varying microstructure. So the processing history of the PLA material must be considered prior to extrusion into a scaffold (Fig. 3).

\section{Experimental testing on virgin PLLA samples}

Specimens for testing of materials for bioresorbable scaffolds come in a variety of forms from fibre to dogbone and the whole scaffold. Thus, each set of data is specific to the used configuration and does not represent general PLLA behaviour. With complex scaffold geometries, it becomes apparent that there is no simple way to test complex mechanical behaviour, especially in localized areas.

Zilberman et al. (2005) assessed behaviour of PLLA fibres and stent structures by subjecting them to uniaxial tensile testing. PLLA revealed high levels of tensile strength and modulus in comparison to other biodegradable polymers tested, polydioxanone (PDS) and poly(glycolide-co-epsiloncaprolactone) (PGACL) (Table 5). From Fig. 4, it is apparent that PLLA is the only polymer which exhibits yield.

Engels et al. (2009) assessed the performance of amorphous PLLA materials under short- and long-term static loading conditions to investigate the timedependent failure behaviour, especially the molecular and kinetic mechanisms which cause this time dependence. They found that premature failure seen in polylactides was due to the time-dependent behaviour of the materials, a common feature of polymer materials. The
Table 5 Mechanical properties of bioresorbable fibres obtained in tension testing (Zilberman et al. 2005)

\begin{tabular}{llll}
\hline Fibre & Tensile strength (MPa) & Modulus (MPa) & Strain (\%) \\
\hline PLLA & 967 & 5000 & 50 \\
PDS & 583 & 367 & 161 \\
PGACL & 721 & 477 & 151 \\
\hline
\end{tabular}

work assessed compression behaviour of PLLA under a range of applied strain rates. As illustrated in Fig. 5a, PLLA initially behaved as a linear viscoelastic material, and changed to a non-linear response with increasing stress levels. A yield point of the material appeared at around $4 \%$ strain level with stress of $94 \mathrm{MPa}$. The initial response exhibited the trend for a typical brittle material, a dominant characteristic of PLLA, but strong softening (decreasing stress with increased strain) was followed by some hardening (upward trend of stress versus strain and large stretching before failure) (Meijer and Govaert 2005). Creep deformation of PLLA (Fig. 5b) is characterised by a sudden increase in strain to the point of final failure, which happened after some $30 \mathrm{~min}$ of the application of the stress equal to $70 \%$ of the yield point (Engels et al. 2009). An additional factor, which may affect the time-dependent performance of PLLA, is the application of dynamic load caused by blood pressure.

Bobel et al. (2015) recently characterized pre-degradation characteristics of PLLA used for cardiovascular application, as there remained a lack of data in this area. Performance of PLLA was strongly dependent on temperature and strain

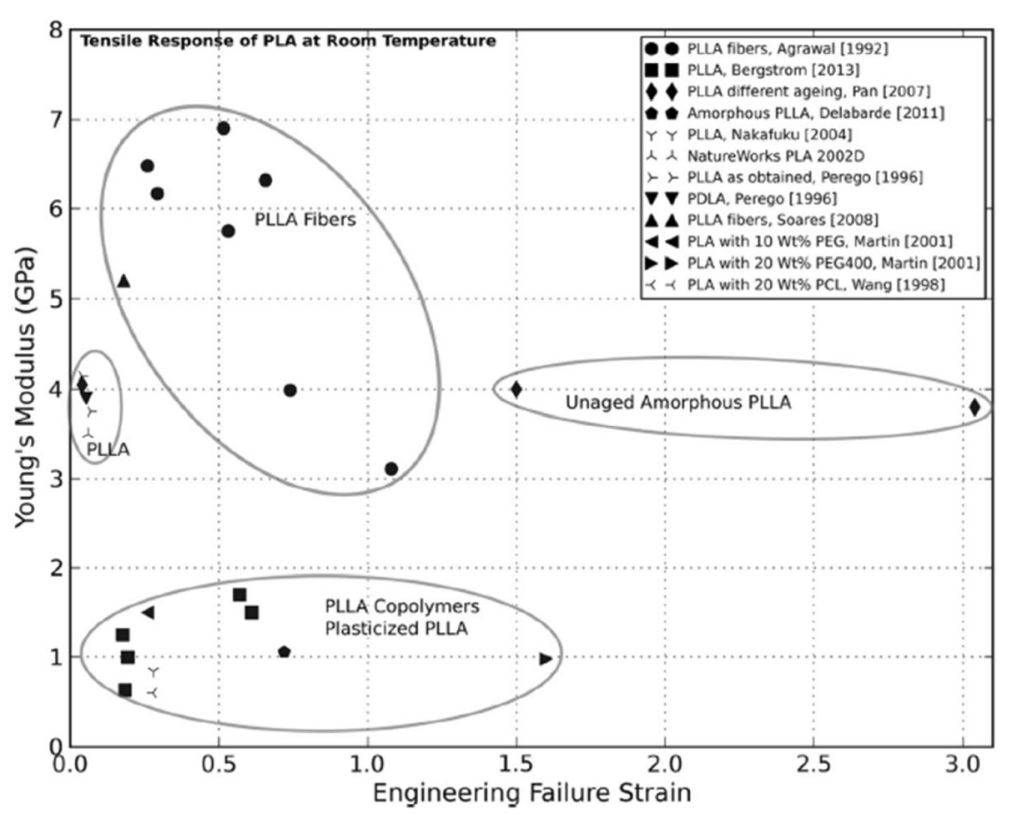

Fig. 3 Overview of the summarizing link between Young's modulus and material microstructure (Agrawal et al. 1992; Perego et al. 1996; Wang et al. 1998; Middleton and Tipton 2000; Hermawan et al. 2010; Sin et al. 2012; Söntjens et al. 2012; Deroiné et al. 2014; Nerkar et al. 2014; Bergstrom and Hayman 2016) 


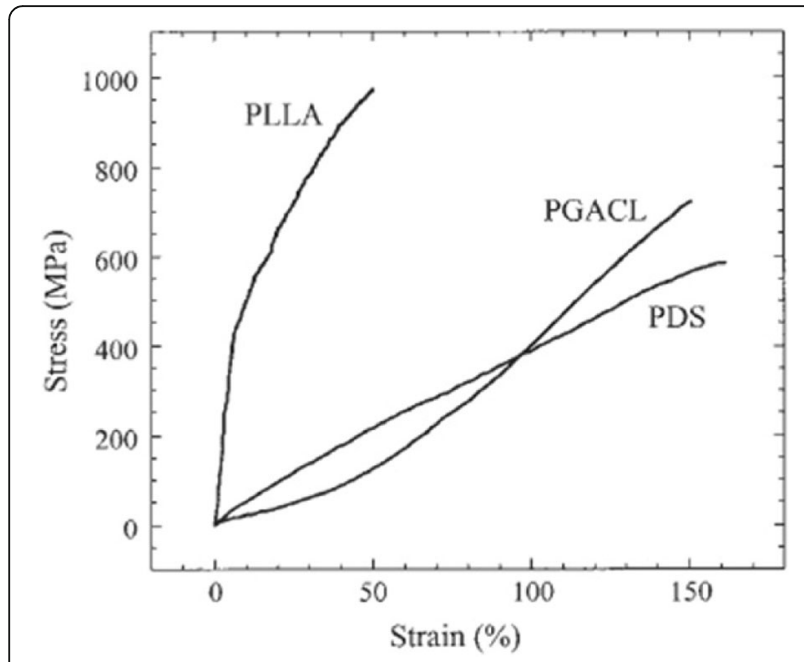

Fig. 4 Stress-strain curves for different bioresorbable fibres (Zilberman et al. 2005)

rate, and overall strain was revealed to contain a significant recoverable component. These factors were demonstrated at a displacement rate recommended for Absorb scaffolds (Abbott vascular, U.S.A.) [2.5 mm/min] (Fig. 6), which is the suggested inflation rate for scaffold deployment (Abbott Absorb and Absorb GT1, 2016). Work by Wang et al. (2017) presented uniaxial tensile tests on high molecular weight PLLA at two temperatures in order to correctly replicate mechanical behaviour of stent crimping $\left(48{ }^{\circ} \mathrm{C}\right)$ and expansion $\left(37{ }^{\circ} \mathrm{C}\right.$ - body temperature) (Fig. 7). The obtained results demonstrated good plasticity of the material and a steady state of stress evolution in the material after yield stress was reached.

The testing schemes employed mostly two types of specimens- fibres and dogbone samples make of bulk material. Obviously, these specimens, generally, were not exposed to the same manufacturing/ processing conditions as a whole scaffold, questioning the suitability of obtained results to analysis of scaffolds. To overcome

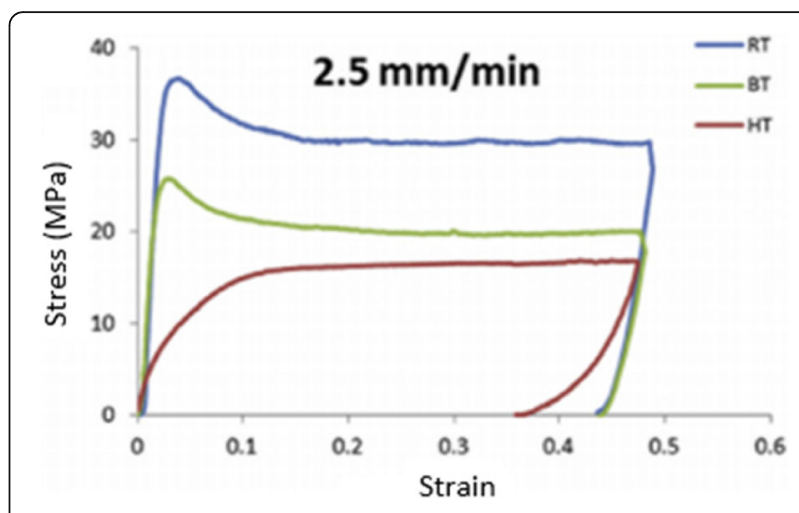

Fig. 6 Experimental stress-strain behaviour with maximum displacement of $50 \%$ at different temperatures (RT, BR \& HT are room, body and high temperatures respectively) (Bobel et al. 2016)

these limitations, post-manufacture tests of scaffolds were performed.

\section{Scaffold testing}

Testing the macro properties of a scaffold is difficult to pursue due to their intricate geometry. At present, there is one set of ASTM guidelines for testing of absorbable stents (ASTM 2013) but they do not capture mechanics of the whole device before and during implantation and degradation. Eswaran et al. (2011) carried out a ring-test experiment, using Absorb scaffold, to quantify its mechanical data. Geometry of the ring was non-uniform around the circumference; therefore, it could be assumed that, due to this, mechanical properties of the scaffold differed around the ring. The ring-tension experiments showed a breakage just below $3 \mathrm{~N}$ (Fig. 8a). To ensure the material tested was comparable to that of final stent, dog-bone samples used for tension testing were subjected to manufacturing processes that a scaffold tube would undergo. Figure $8 \mathrm{~b}$ illustrates material anisotropy after yield and the flow resistance in the circumferential direction continues to grow post yield; however, in the axial direction, there was a weaker
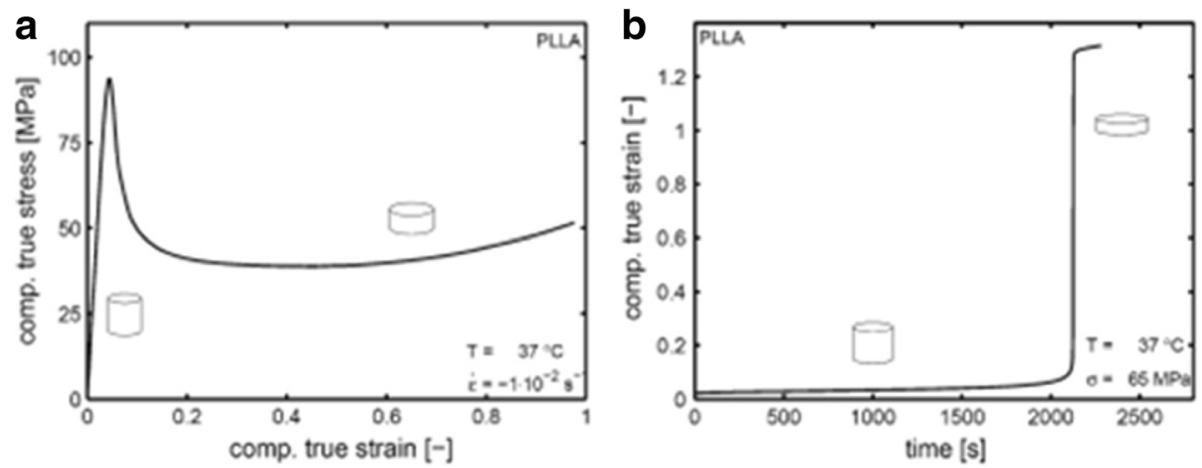

Fig. 5 (a) True stress versus strain (compressive) at constant strain rate; (b) evolution of compressive true strain with loading time at constant stress (Engels et al. 2009) 


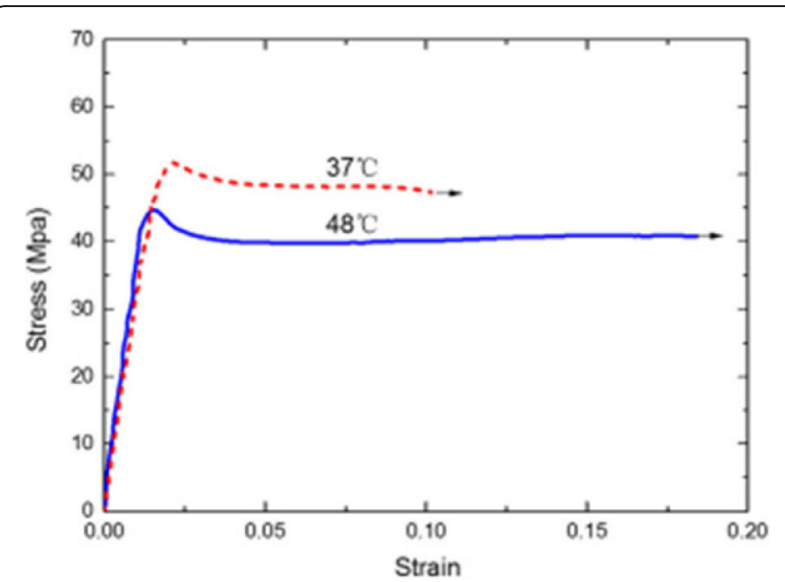

Fig. 7 Stress - strain curves for PLLA at crimping and expansion temperatures (Wang et al. 2017)

response with necking occurring. The displacement rate for testing is also shown to have an influence. Typical for PLLA, the material response was found to be strainrate-dependent.

Oberhauser et al. (2009) investigated the Absorb scaffold by considering change in radial strength and molecular weight over time with incubation up to 90 days. It can be seen that Absorb stents had a radial strength comparable to that of common metallic stents (Fig. 9). This is despite weak bulk mechanical properties of polymers in comparison to their metallic counterparts and due to postextrusion manipulations with polymeric tubes increasing the circumferential orientation of crystallites in the semicrystalline PLLA structure, resulting in higher resistance to radial loading (Oberhauser et al. 2009).

Additional data for Abbott Vascular stents (Fig. 10) show the evolution of pressure against the scaffolds'

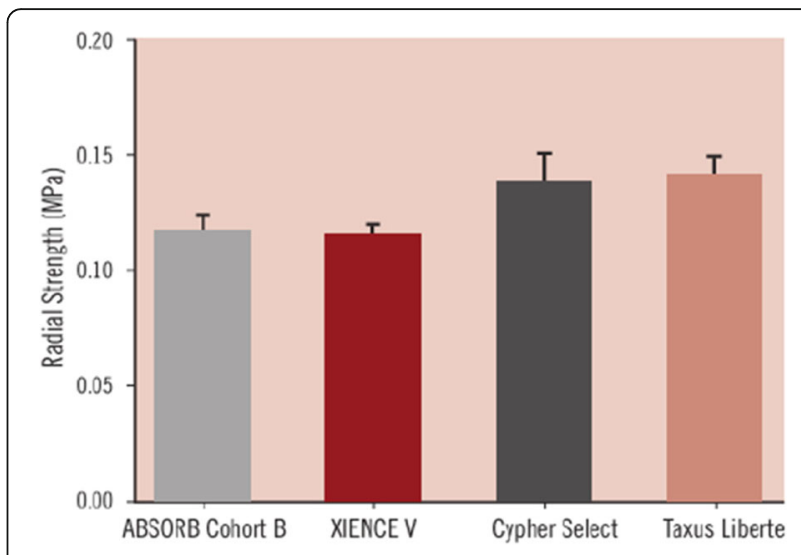

Fig. 9 Radial strength data for polymeric and metallic stents (Oberhauser et al. 2009)

outer diameter with degradation times, obtained by using a MSI RX550 Radial Force tester. The data show a noticeable change in behaviour with the onset of plastic deformation. For periods shorter than 12 months, the scaffold plastically deformed under larger compressive loads. However, it was still able to maintain radial support to the artery beyond the yield point. For implantation longer than 12-months, a reduced resistance of stents to compressive load was found, indicating a lack of integral support to a vessel wall. This testing strategy is essential to observe maintenance of vessel patency is maintained during critical months of vessel healing (Kossuth et al. 2017).

Other features also affect mechanical properties of PLLA stents. Gomez-Lara et al. (2011) investigated the variation in curvature and angulation of the treated vessel post-deployment of BRSs. Absorb, in comparison to metallic stents, presented better conformability to vessel's
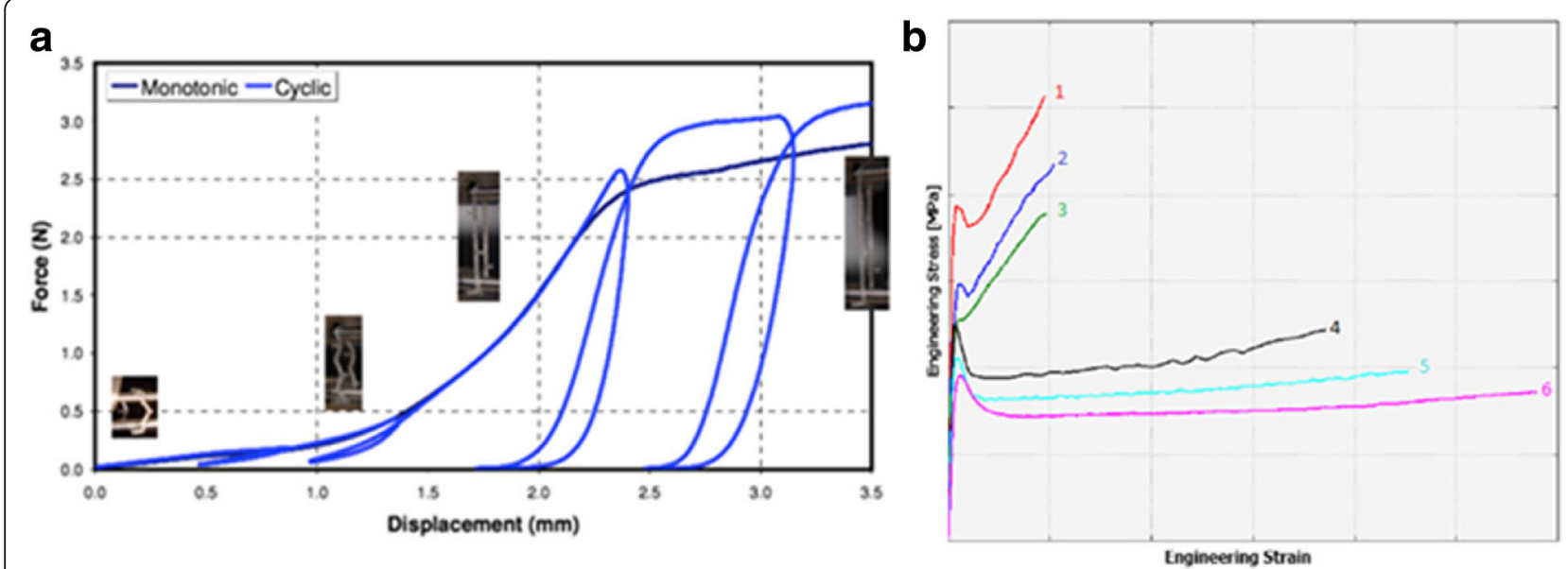

Fig. 8 (a) Average force-displacement average curves from ring-tension experiment; (b) stress-strain data for uniaxial tension (1 - circumferential-fast; 2 - circumferential-medium; 3 - circumferential-slow; 4 - longitudinal-fast; 5 - longitudinal-medium; 6 - longitudinal-slow) (Eswaran et al. 2011) 


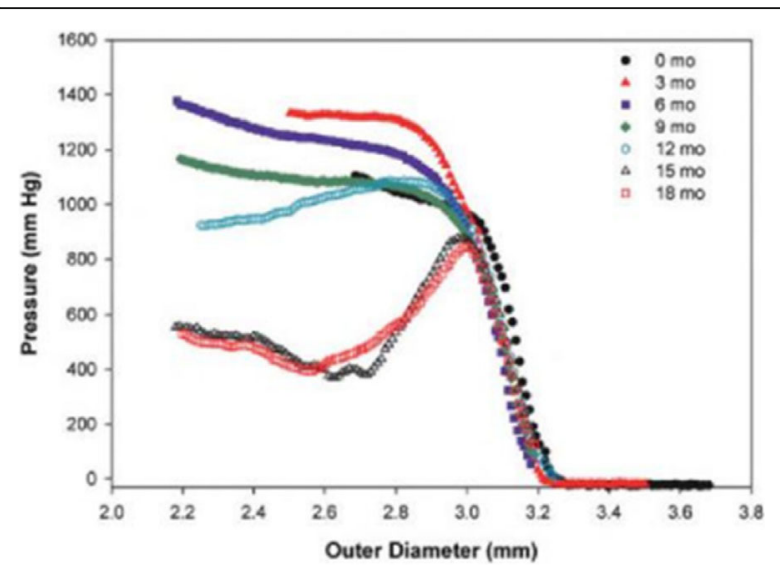

Fig. 10 Pressure vs. outer diameter post-deployment for samples with varying degradation times (Kossuth et al. 2017)

architecture and produced lower variations of these parameters (Gomez-Lara et al. 2010). In 2011, the same authors demonstrated that BRS restored coronary configuration in comparison with metallic stenting which altered geometry permanently (Gomez-Lara et al. 2011). Foin et al. (2016) assessed overexpansion of Absorb scaffolds beyond their recommended diameter and concluded that this could result in strut breakage and a loss of central mechanical support. A similar work was conducted and corroborated by Ferdous et al. (2015).

A comprehensive overview of in-vitro tests assessing mechanics associated with the safety and efficacy of the implantable devices was presented by Schmidt et al. (2016). Scaffold expansion, elastic recoil, radial strength and flexibility/ bending stiffness were assessed for two types of virgin bioabsorbable scaffolds and one metallic stent. As expected, the Absorb scaffold demonstrated lower crush resistance in comparison to a metallic stent; however, the collapse pressure for Absorb (172 kPa) was in the required range for radial strength of permanent stents (Fig. 11; Lanzer and Schmidt 2015). This data corroborates with that produced by Oberhauser et al. (2009), where strength of polymer scaffolds was comparable to that of their metallic counterparts. Elastic recoil of the stents was assessed immediately after implantation and an hour after expansion in two vessel types, i.e., rigid (Fig. 9b) and mock vessels (Fig. 9c). Within the rigid vessel, the Absorb scaffold exhibited recoil comparable to that of BIOTRONIK; however, it did not display the interesting behaviour of DESOLVE, whose diameter increased after an hour. The mock vessel did not affect the BIOTRONIK stent, but encouraged further recoil of the Absorb scaffold after an hour of implantation and significantly increased recoil of the DESolve scaffold. These results illustrate that it is crucial to correctly simulate in-vivo conditions as they may impact a stents performance. With load, the Absorb scaffold did recoil further, as expected. The authors noted that good in-vitro performance would not always correlate to good performance in-vivo, and poor in-vitro performance is indicative of potential complications. These obtained results showed the high performance of PLLA and, in particular, the Absorb scaffold in comparison to metallic counterparts.

\section{Mechanical performance of scaffolds with degradation}

Obviously, in-vitro degradation of bioresorbable stents has a strong effect on their mechanical properties and

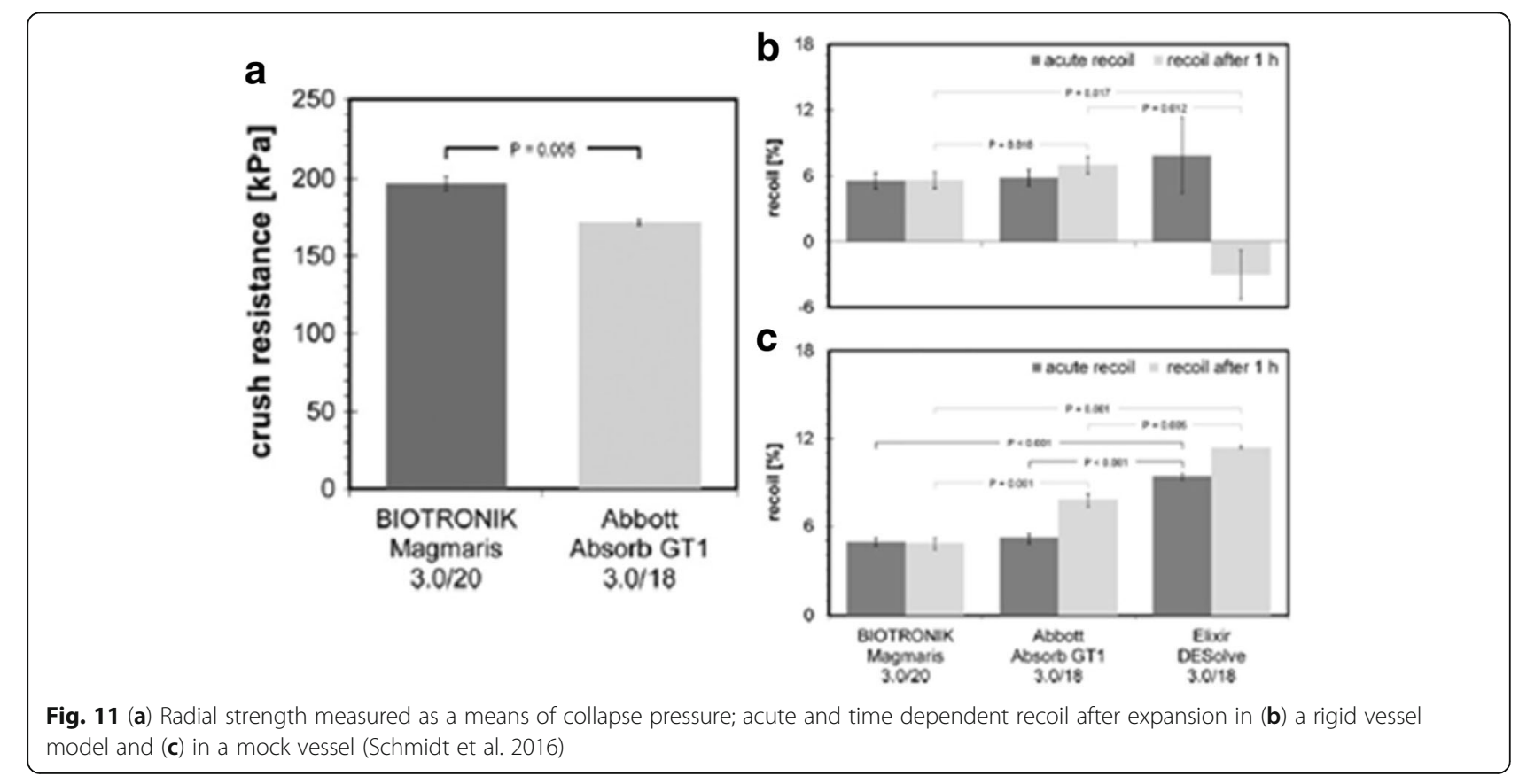


performance. Degradation is defined as the "chain-scission process, during which polymer chains are cleaved to form oligomers and, finally, to form monomers", whereas erosion "designates the loss of material owing to monomers and oligomers leaving the polymer" (Göpferich 1996). There are two methods of hydrolysis which PLLA can undergo: (1) chemical degradation via hydrolysis and (2) enzyme-catalysed hydrolysis; the former is the most prominent for artificial biodegradable polymers. Degradation of polymers such as PLLA depends on parameters of the environment, only some of which are controllable; these include the type of chemical bond, $\mathrm{pH}$ level, molecular weight, polydispersity, crystallinity, morphology, ionic strength, temperature and water uptake (Göpferich 1996; Gong et al. 2007; Zhang 2015).

Degradation of PLLA fibres in vitro were investigated by Yuan et al. (2002) with fibres incubated in phosphate buffer solution (PBS) with pH 7.4 and at 37 C for 3545 weeks. The average molecular weight of fibres, produced by melt spinning, dropped throughout degradation, with $40-60 \%$ reduction at the end of the incubation period and an increase in crystallinity. Fibres studied by the group were not investigated separately, instead, they were bundled together randomly which may have affected their biodegradation. PBS was changed fortnightly which is an acceptable time frame in accordance with ASTM standards. Prior to measurements of degraded samples, a bundle was removed from PBS, washed with water and dried in a vacuum oven at $48 \mathrm{C}$. Water absorbed by the fibres is a potential issue that could affect the results of this scheme. However, authors did not mention duration of this process. Additionally, drying in a vacuum oven is a good methodology to remove excess fluid from the fibres; however, a temperature of $48 \mathrm{C}$ could affect the properties of the fibre, with potential to cause damage to the polymer. The group could have weighed fibres prior incubation in the vacuum oven in order to assess the water content in the material (Yuan et al. 2002).

Mechanical, rheological, fatigue and degradation behaviour of PLLA used in vascular implants was investigated by Bartkowiak-Jowsa et al. (2012). The authors highlighted the importance of adequate optimization of stent design. The study produced results (Fig. 12) confirming the need to change the incubation fluid at regular intervals. A sawtooth character of the graph demonstrates that the incubation fluid required regular replenishment to maintain a $\mathrm{pH}$ of $7.4 \pm 0.2$. PLLA tested in this regime did not show a decrease of more than $10 \%$ in strength and deformability, ideal for providing sufficient support for an arterial wall. However, it was noted that the total degradation time for PLLA was 24 months, far beyond the time required for tissue regeneration. In order to combat this, the authors suggested the modification of PLLA through the addition of biodegradable filler, alginate fibres. These

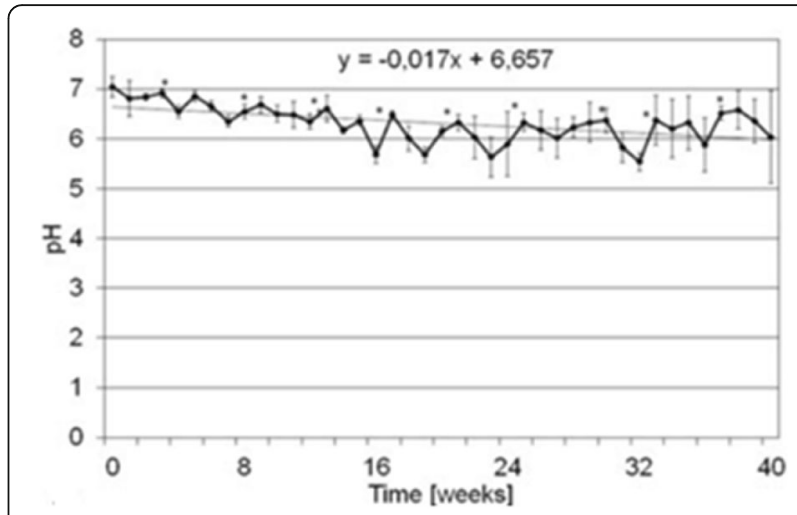

Fig. 12 Evolution of pH of PLLA incubation solution over time (Bartkowiak-Jowsa et al. 2012)

fibres enhance liquid absorption at phase boundaries resulting in faster degradation, without affecting mechanical properties of PLLA. The study assessed the stability of elastic properties by testing their thermodynamic properties. Assessing the storage-modulus values allowed the authors to determine the temperature range, in which the material demonstrated the desired elastic properties. All materials tested had glass-transition temperatures in the range of 56.1-68 $\mathrm{C}$ providing structural stability in the temperature range of biomedical applications.

Kimble and Bhattacharyya (2015) assessed mechanical properties of PLLA during in vitro degradation in comparison to a co-polymer material (PLLA/PBS) by incubating dogbone specimens for 24 weeks in PBS at $37{ }^{\circ} \mathrm{C}$. In comparison to the co-polymer tested, neat PLLA maintained integrity throughout 24 weeks, showing increasing creep resistance in the initial 8-week degradation period. The initial modulus and tensile strength of PLLA are higher than those of a variety of co-polymer blends. The study demonstrated the necessity to obtain baseline properties of a material and that the copolymeric blend in fact had lower mechanical properties and a higher, less stable degradation rate. The effect of fatigue on chemical and mechanical degradation of model stent sub units was analysed by Dreher et al. (2016) since this factor can impact greatly on a stent's performance and was studied insufficiently. Subunits composed of PLLA were exposed to fatigue and degradation conditions simultaneously, amounting to one year of implantation within the body. Preliminary experiments, carried out by the authors, illustrated that 38 million fatigue cycles were concurrent with one year of implant of the scaffold within a pulsatile vessel. In comparison to control samples tested under static conditions (i.e. without fatigue), the study indicated that fatigue loading, resulted in a significant increase of samples stiffness with a diminished force at break. Molecular 
weight was also affected, with a greater decline seen at fatigue. The authors concluded that this illustrated a link between chemical degradation and mechanical loading.

The effect of degradation on tensile mechanical properties of PLLA fibres and expandable stents prepared from fibres was studied by Zilberman et al. (2005). The work discovered that PLLA, in contrast to other bioabsorbable materials, underwent degradation at a slower rate, displaying no alterations in mechanical properties during 6 weeks (Fig. 13). It also confirmed results of the previous study by the same group, showing PLLA fibres exhibited good mechanical properties after 24 weeks of degradation incubation (Zilberman et al. 2004). Single fibres constructed into a stent structure for each polymer were subjected to radial compressive tests (Fig. 14) to obtain data for scaffold strength. PLLA showed consistent results over the 6-week period and confirmed its viability for use as an arterial support structure.

Dreher et al. (2015) focused on assessing the process of degradation of PLLA tubes in in-vivo tests as a model for coronary stent degradation. Their predominant aim was to estimate the effect of physiological factors, (pulsatile flow, body temperature), in testing of scaffolds. Their work demonstrated that PLLA tubes subjected to mock pulsatile flow displayed a statistically different degradation pattern to tubes subjected to control conditions (inside the vessel but not subjected to pulsatile flow). The results indicated that to correctly investigate performance of polymeric scaffolds in-vivo, all constituents that stimulate degradation such as correct pulsatile flow, pressure, and temperature should be implemented invitro to obtain accurate results. After 6 months, it was seen that the scaffold in the loop set up presented a slower rate of molecular weight loss compared to the control samples. This was potentially due to oligomers, breakdown products from degradation, being removed with the flow system (as opposed to remaining within the control samples), creating localized degradation because of their acidic nature. Crystallinity changes for

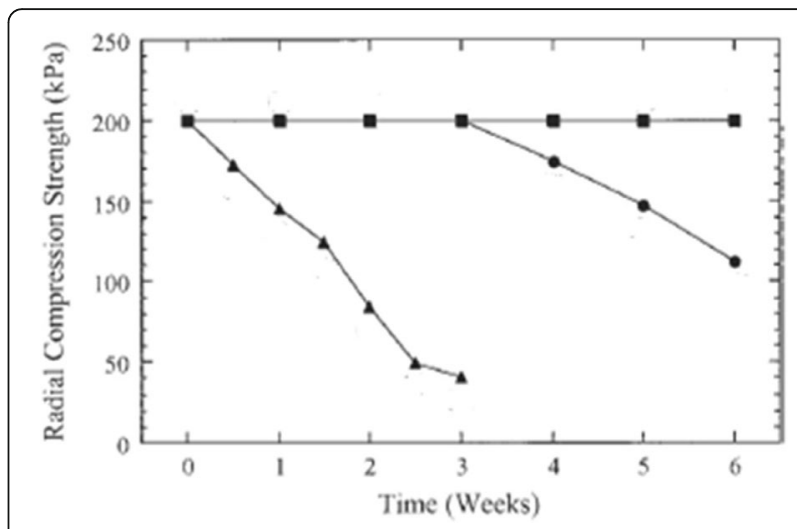

Fig. 14 Radial compression tests for scaffolds comprised of single fibres (PLLA (squares), PDS (circles) and PGACL (triangle) (Zilberman et al. 2005)

control samples were comparable; however, the loop samples showed that crystallinity was diminished significantly. This was accounted for by the group by relaxation of polymer chain with certain stimuli such as frequency and temperature (Fig. 15; Dreher et al. 2015).

The effect of static and dynamic loading conditions on degradation of PLLA stent fibres was assessed by Hayman et al. (2014) over 15 months to ascertain whether dynamic conditions were required during invitro testing and it was found that it did affect output. In comparison to a static load, dynamic load seemed to accelerate degradation, especially at later time point; however an increase in static load also showed accelerated degradation (Hayman et al. 2014). Luo et al. (2014) assessed the degradation performance of highmolecular-weight PLLA scaffolds in a mock artery system. A plasma pump enabled simulation of systolic/ diastolic pressures comparable to those observed in the human circulatory system. The system also enabled incorporation of fluid circulation to mimic blood flow. These data were compared to in-vivo results, where the scaffolds were implanted into animal models. There was a good correlation between the in-vivo and in-vitro results, and the slight discrepancies between the two conditions

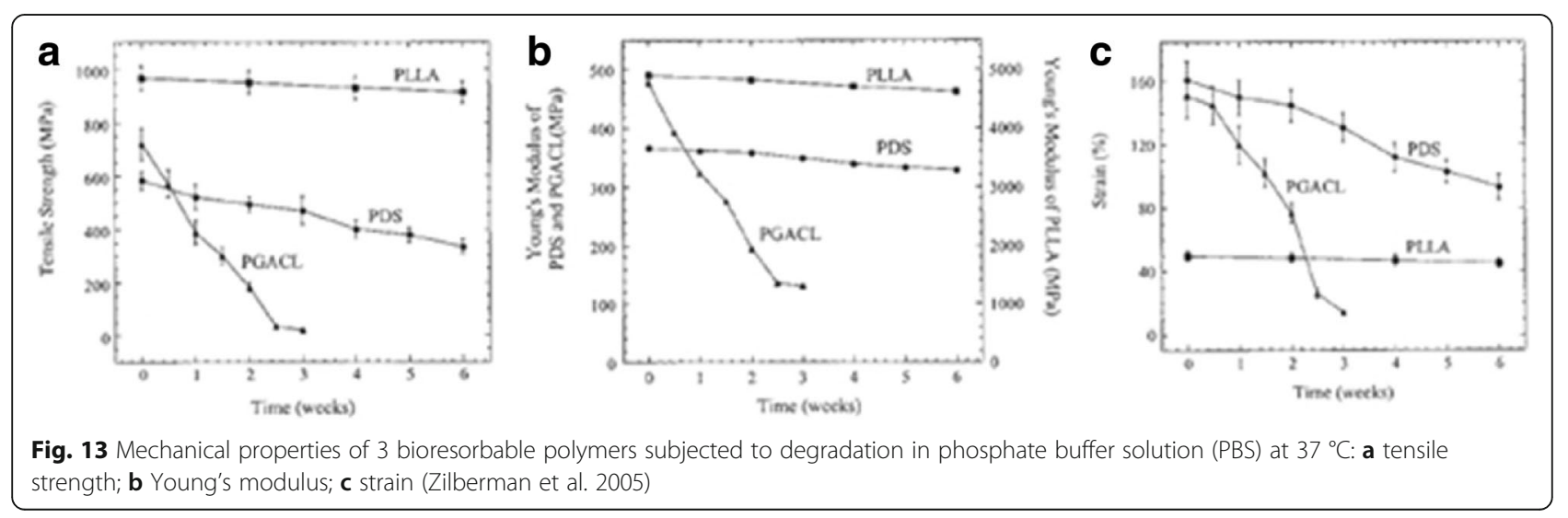




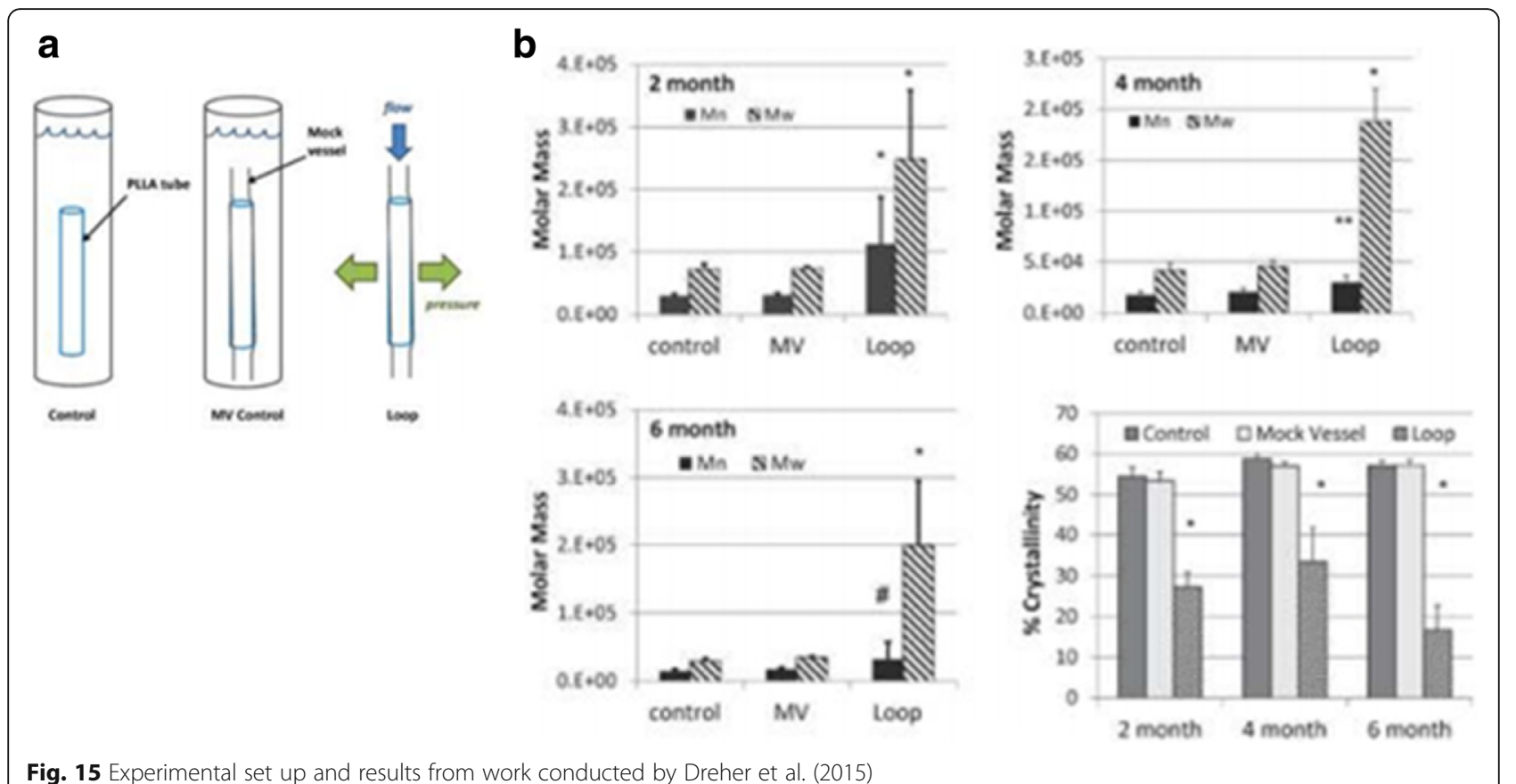

might be attributed to the biochemical environmental difference (Luo et al. 2014).

From this review of degradation, manufacturing and processing studies for PLLA, it can be concluded that a significant number of factors affect mechanical properties of PLLA scaffolds, from its initial post-implantation state and throughout degradation. Each PLLA material, depending on these conditions, can result in significantly altered mechanical properties and degradation profiles. Degradation performance of biodegradable polymers invitro showed that higher loads resulted in shorter degradation times (Athanasiou et al. 1998; Middleton and Tipton 2000); therefore accurate simulation of mechanical conditions corresponding to real-life conditions (e.g., pulsatile flow and loads) is needed. Additionally, many studies appeared to use PBS as a fluid to incubate scaffolds; however, the biochemical environment may also influence polymer degradation. Obtaining accurately quantified mechanical response data can then be used as input into a constitutive model for finite-element (FE) simulations (Bobel et al. 2016). This could diminish experimental efforts and enable accurate prediction of scaffold performance throughout its lifecycle.

\section{Computational studies for BRS performance with degradation}

Numerical simulations, based on adequate mechanical models allow additional insights into a response of a physical system to specific loading and environmental conditions that can be used for making decisions from an engineering perspective (Babuška 1991). Computational modelling of medical devices enables the users to obtain knowledge of their performance and precise locations of failure in a device, implement design optimization and reduce benchtop testing thus minimizing the device development time and cost (Eswaran et al. 2011; Bobel et al. 2015). The ability to accurately capture the behaviour of medical-device materials under physiological loads and during processing remains a challenge. There appears to be a lack of material models detailing the accurately the degradation process of bioabsorbable materials because of a wide range of factors affecting on a materials response, e.g., temperature, processing and extrusion procedure. Simulations run with FE analysis for complex loading conditions require precise experimental investigation into the modelled material in order to obtain fundamental geometric and material parameters (Bobel et al. 2015). Through development of accurate validated computational models, high-quality predictions of device performance are possible (Eswaran et al. 2011). Due to the complexity and limited work carried out in the area of numerical simulations of PLLA BRSs, this section highlights the recent studies.

\section{Material modelling of PLLA}

Mechanically, PLLA is an anisotropic, viscoelastic material, with its response characterized by rate-dependent viscoplasticity (Eswaran et al. 2011). This time-dependent behaviour of the material is also influenced by temperature, surrounding environment and processing conditions, commonly observed in polymers (Grabow et al. 2005). Given these varying factors, it is critical that material characterization and responses of its specimens and entire 
devices are adequately captured by the model to provide accurate predictions. At low strains, the behaviour of this material is viscous whereas under high strain, it behaves as brittle elastic material (Bardenhagen et al. 1997). A nonlinear mechanical response of PLLA is due to its low glasstransition temperature $\left(\mathrm{Tg}=60^{\circ} \mathrm{C}\right)$, sensitivity to molecular weight, degree of crystallinity and physical ageing time (Bergstrom and Hayman 2016). Classical linear viscoplastic/elastic models therefore cannot be used to describe PLLA behaviour as they do not capture its full anisotropic behaviour (Eswaran et al. 2011). Also typical elastic, hyperelastic or viscoelastic models are not able to capture the accumulation of plastic strain in a material, which is crucial for engagement of vascular scaffolds (Vieira et al. 2015).

Neo-Hookean or Mooney-Rivlin models, describing incompressible hyperelastic materials, could be used to predict material behaviour prior to any fissure of nondegraded PLLA. These models are useful as they can predict monotonic behaviour of PLLA devices, also at specific degradation time points. Mechanical behaviour of PLLA, with large deformation and dynamic loads at different strain rates, is both viscous and elastoplastic. Also, hysteresis behaviour was observed in biodegradable polyesters (Vieira et al. 2015). A handful of models at present account for diverse behaviours of aliphatic polyester using varying combinations of hyperelastic, viscous and plastic models; however, they do not account for the degradationrelated changes (Vieira et al. 2015). As scaffolds are subjected to loading above the elastic limit during processing/ manufacturing, it leads to an accumulation of plastic strain and contributes to device failure at these areas of high strain. Post-implantation scaffolds are also subjected to a cyclic stresses, which could cause evolution of significant plastic strain during their in-service life resulting in failure and laxity (Vieira et al. 2015). Hydrolysable bonds in PLLA make the material more susceptible to moisture, heat, light and mechanical stresses. The traditional degradation mechanism of biodegradable polymers is chemical degradation via hydrolysis or enzyme-catalysed hydrolysis. Importantly, mechanical behaviour of the material evolves with time due to the hydrolytic chain scission (Pan 2015). Degradation results in a reduction in molecular weight of such polymers, there is also a reduction in its ductility, toughness and strength (Vieira et al. 2015). Some complex material models based on a concept of networks, combining elastic, sliding and dissipative elements (based on Boltzmann's superposition principle), are used to simulate this time dependent response; however, most models only simulate an initial mechanical response of the polymer and neglect changes in material properties during hydrolytic degradation (Vieira et al. 2015).

\section{Constitutive material models}

Tailoring microstructural parameters for specific functions are depends on potential applications; these parameters can be controlled with resin formulation and processing conditions. Stress-strain, deformation and degradation responses of a material is affected significantly by a type of, and changes in, applied boundary conditions, loads and environmental factors, the material is subjected to. Such multi-physics responses can be incorporated into relevant constitutive models to simulate material behaviour; however, there remains doubts as to whether a whole-device response is accurately captured in simulations (Bergstrom and Hayman 2016). A stent technology and mechanical behaviour of metallic stents are relatively well established; however, due to the non-linear, viscoplastic and degradable behaviour of PLLA along with an altering mechanical response of the device in-vivo, the performance of BRSs with degradation is not as established (Bergstrom and Hayman 2016). The ideal material model for the Absorb PLLA scaffold should be able to capture the nature of the mechanical properties of the stent with evolving degradation. As highlighted in Table 6, numerous materials modes were proposed in literature to capture complex responses of biodegradable polymers - from their virgin state right through to full degradation (Soares et al. 2008, 2010a, b; Eswaran et al. 2011; Muliana and Rajagopal 2012; Khan and El-Sayed 2013; Vieira et al. 2015; Rosa et al. 2016). The past five years have seen significant advancements in computational mechanics of bioresorbable scaffolds aimed at development of material models to capably simulate adequately performance of PLLA stents.

\section{Computational and mathematical modelling of BR scaffolds}

Various groups of researchers concentrated on different aspects of simulation of properties and performance of

Table 6 Different material model frameworks used for modelling of PLA (Soares et al. 2008; Eswaran et al. 2011; Söntjens et al. 2012; Khan and El-Sayed 2013; Hayman et al. 2014; Bergstrom and Hayman 2016)

\begin{tabular}{llllll}
\hline Model & Class & Degradation modelled & Visco-plastic effects & Anisotropic effects & Use in FE simulations \\
\hline (Eswaran et al. 2011) & Viscoplastic & $x$ & $\checkmark$ & $\checkmark$ & $\checkmark$ \\
(Hayman et al. 2014) & Hyperelastic & $\checkmark$ & $x$ & $x$ & $\checkmark$ \\
(Khan and El-Sayed 2013) & Linear viscoelastic & $\checkmark$ & $x$ & $x$ & $\checkmark$ \\
(Soares et al. 2008) & Hyperelastic & $\checkmark$ & $x$ & $x$ & $\checkmark$ \\
(Söntjens et al. 2012) & Viscoplastic & $\checkmark$ & $\checkmark$ & $x$ & $x$ \\
\hline
\end{tabular}


bioresorbable stents. Bobel et al. (2015) compiled a comprehensive study of computational bench testing using Abaqus/Standard 6.12 (SIMULIA), to evaluate shortterm mechanical performance of three different stent designs; however, with no consideration for polymeric degradation. A non-linear viscoelastic parallel network model was used to account for material performance; still, there was no account for materials plasticity. Whilst some more complex material representations are available, the group discussed the advantage of this model, including its ease of use and access in Abaqus software, which captures PLLA behaviour for the testing methodologies involved sufficiently well. An interesting notion is a "flexible" material model, where a range of elastic behaviours and properties of PLLA can be incorporated in it. Still, this model is only suitable for material behaviour at so called "time zero" (i.e. immediately post deployment). A strong feature of this work is the use of real stent geometries and experimental testing to assess the radial strength, flexibility and longitudinal resistance (Fig. 16). Additionally, shorter sections of stents were used, 2 or 4 circumferential rings, to reduce the computation time. There was a special focus on ensuring that the stents were exposed to the same real-life processes prior to implanting (e.g. expansion). Authors found that to meet the requirement of minimum collapse pressure of $0.04 \mathrm{MPa}$, the Young's modulus of $4.1 \mathrm{GPa}$ was required for Absorb scaffolds. This was conflicting information based on an Abbott patent report, stating that PLLA has a modulus of 1.2-2.7 (Wang 2013). So, it would have been more accurate to accommodate this range of values in the employed material model. The radial strength of the Absorb scaffold was reported to be comparable to that of metallic stents (Oberhauser et al. 2009), so long as they were deployed within their size limits, these experimental data contradict the computational results of this work. It was suggested that to improve the radial performance of stents, the materials elastic modulus should be increased to $15 \mathrm{GPa}$. This, however, would affect the compliance mismatch which is a goal for bioresorbable scaffolds (Brugaletta et al. 2012). According to this study, the wide variations in the polymer's elastic modulus resulted in a corresponding range of stent resistance to applied pressure, with weaker materials prone to collapse under lower pressure. Additionally, strut thickness was assessed computationally and it was found that as in the experiments, thicker struts could bear higher radial pressure than thinner struts. Finally, assessing a range of stent geometries, the mechanical performance of scaffolds was directly linked to their design and dimensions (Bobel et al. 2015). Schiavone and Zhao (2016) corroborated the factor emphasised in Bobel et al. (2015), that it is essential relevant biomechanical forces in the model are incorporated in computation performance studies in order to correctly simulate all steps of a scaffold lifecycle, from manufacturing to full degradation.

In another study Luo et al. (2014) conducted comprehensive in-vitro and in-vivo analysis to validate their model by employing a user-defined constitutive model (USDFLD) in FE simulations. In this approach a user can manually define different field variables in order to account for material properties at a certain time point. Incorporating varying degrees of degradation into the material model enabled assessment of evolution of stent properties with time. Numerical simulations were carried out using Abaqus, with C3D8I element used to mesh the geometric model. This incompatible-mode eight-node brick element was preferred to model stents with Abaqus as they are loaded predominantly in bending (Pham et al. 2014). Crimping and expansion tools were meshed with a surface element (SFM3D4R) and scaffold simulation carried out in four steps (Table 7). These steps were necessary to assess the forces the scaffold is exposed to prior to its implantation into an artery. A fatigue simulation was also conducted to ascertain the effect of pulsatile flow on the change in mechanical properties with time. In this simulation, the last effect was incorporated by application of pressure to the inner arterial walls. This stage was followed by simulations of the degradation process.

Figure 17a demonstrates the von Mises stress for crimping to $1.5 \mathrm{~mm}(\mathrm{~A})$ and expansion (B). Stresses were localized in the U-bend regions of the scaffold, common for polymeric stents (Schiavone et al. 2017). The stage of elastic recoil saw a stress decrease from $161 \mathrm{MPa}$ to 102.4 MPa. In expansion, stress concentration was again found in the U-bend regions, with a high tensile stress of

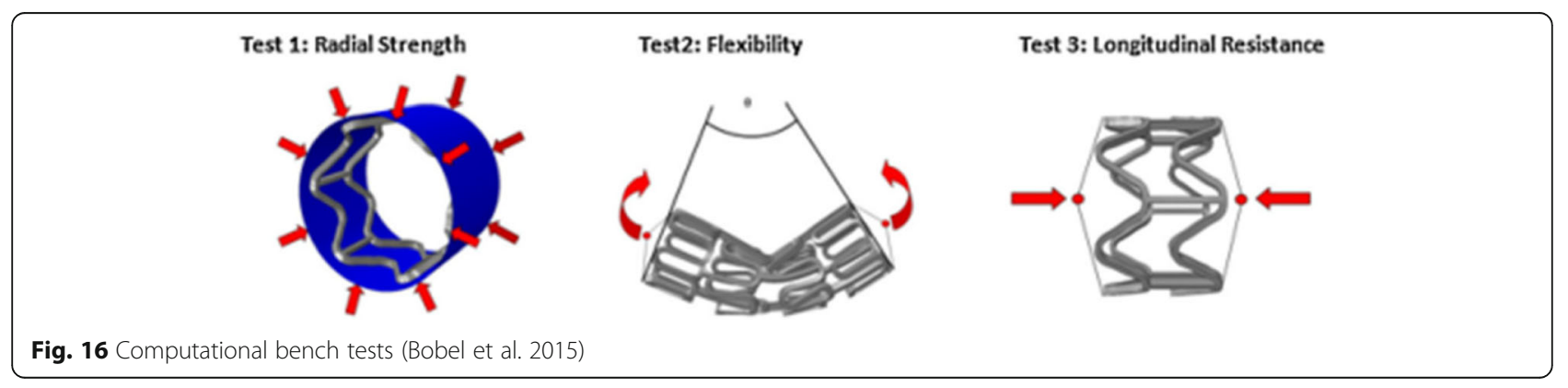


Table 7 Scaffold simulation steps (Luo et al. 2014)

\begin{tabular}{lll}
\hline Step & Detail & Description \\
\hline 1 & Crimp & $\begin{array}{l}\text { Rigid cylindrical tube to simulate a crimp } \\
\text { tool }(3.5 \mathrm{~mm} \rightarrow 1.5 \mathrm{~mm})\end{array}$ \\
2 & Elastic recoil & $\begin{array}{l}\text { Removal of rigid cylindrical tube } \\
\text { Rigid cylindrical body denoting balloon } \\
\text { catheter }(\rightarrow 3.2 \mathrm{~mm} \text { inner radius })\end{array}$ \\
4 & Expansion & Removal of rigid cylindrical tube \\
\hline
\end{tabular}

172.3 MPa. The degradation process was assessed postfatigue, thus ensuring the material state was as in-vivo, with a similar application of biomechanical forces. It was observed that degradation occurred at a greater rate in areas of previous higher strain, presenting spatially nonuniform degradation throughout the scaffold (Fig. 17b). Performing expansion on the incubated in-vitro scaffolds, the observed areas of breakage coincided with highconcentration areas obtained with FE. Thus, the in-vivo, in-vitro and FE results were consistent, implying suitability of the material model used.

Similar to Luo et al. (2014), Wang et al. (2017) presented a combined experimental and computational study on the mechanical performance of PLLA coronary implants. To implement computation aspect, the Abaqus/ Standard implicit solver was used to estimate radial strength and 3-point-bending performance of stents, with care taken to adhere to ASTM standards to ensure that simulations were as close to the testing protocol as possible. Model geometry closely mimicked that of Absorb, and a mesh of hexahedral C3D8R elements was applied. In comparison to Luo et al. (2014), the crimping and expansion simulations also incorporated the effect of temperature for each of these stages, i.e., crimping was at $48{ }^{\circ} \mathrm{C}$ and expansion at body temperature $37^{\circ} \mathrm{C}$. This was supported by testing pure PLLA at different temperatures and using the obtained data with respective models. Results were acquiescent with those described by Luo et al. (2014); with localization of stress found in U-bends of the scaffolds. Simulations were reliant on the experimental data obtained by the group for crimping, expansion, radial strength and three-point bending. Table 8 presents the correlation between the
Table 8 Summary of results obtained in Wang et al. (2017)

\begin{tabular}{lllll}
\hline & & Experiment & Simulation \\
\hline Recoil \% & Crimping & & & \\
& Outer diameter $(\mathrm{mm})$ & 1.41 & $\mathrm{n} / \mathrm{a}$ & 10.87 \\
& & & \\
& Expansion & & & \\
& Inner diameter $(\mathrm{mm})$ & 3.10 & 4.7 & 4.19 \\
& 3.7 & $\sim 2$ & 2.92 \\
& 3.92 & $\sim 2$ & 1.81 \\
& & 1.55 & 1.46 \\
\hline
\end{tabular}

obtained in-vitro data and computational results. For crimping, the radial recoil ratio was not as critical as that observed for expansion. By over-expanding scaffolds, apparently, recoil was reduced, indicative of plastic deformation in the material. These findings can be used to ensure a suitable recoil effect to prevent mechanical injury to the vessel wall due to excess expansion, resulting in inflammation.

In comparison to Wang et al. (2017), Pauck and Reddy (2015) simulated the radial performance of PLLA stents within a remodelling artery, taking into consideration various geometries for the scaffolds. Material-characterization tests were conducted to obtain accurate data for highmolecular-weight PLLA and used in a standard anisotropic elastic-plastic material model. The data obtained from the material characterisation of PLLA was incorporated into the material model, with all the scaffolds having these same material parameters. Three stent geometries were investigated: one mimicked a typical polymer scaffold (Absorb); a second was with a typical metal-stent design; a third addressed the shortfalls and weaknesses of the other two designs. C3D8RH elements were used in simulations as they were computationally inexpensive thanks to having only one integration point per element. Some hourglassing issues were found for C3D8R, however, this was accounted for by enhancing hourglass control in the simulations. It was concluded that design and geometry of scaffolds had an impact on the radial performance of stents. A geometry of the typical polymer scaffold was shown to provide the best performance in comparison to the other two. It was concluded that all
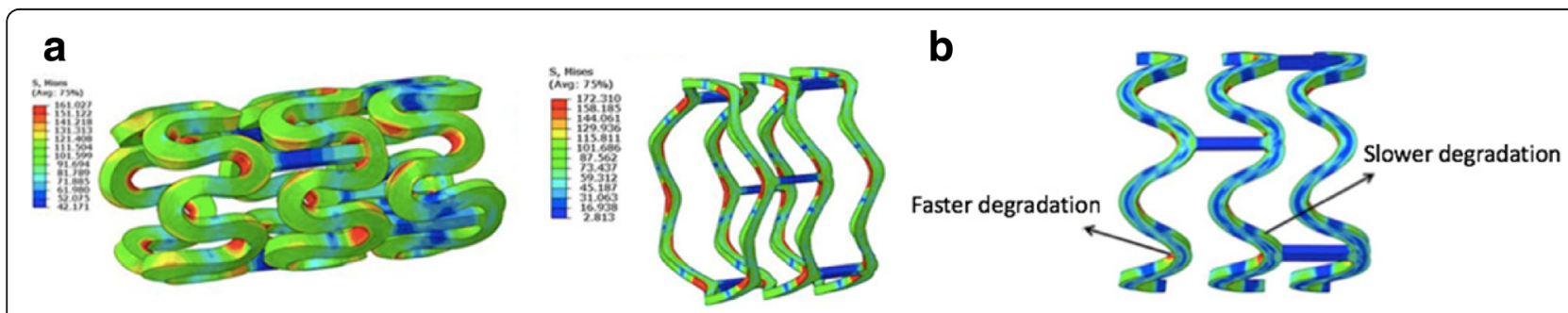

Fig. 17 (a) Results of crimping and expansion simulations and (b) degradation trend at different sites across the scaffold depending on stress (Luo et al. 2014) 
stent geometries underperformed, with the polymer stent only just presenting adequate radial strength of $322 \mathrm{mmHg}$ (magnitudes in excess of $300 \mathrm{mmHg}$ are considered sufficient for vessel patency (Pauck and Reddy 2015)). This radial strength value, however, was only achieved by a significant increase of the material-stiffness to $9 \mathrm{GPa}$. With depleting material stiffness values, the performance of all designs diminished. Additionally, improving thickness of scaffolds improved their performance; however, this, in turn, could instigate damaging physiological side effects.

Additionally a study by Schiavone et al. (2016) highlighted the importance of taking into account variations of plaque morphology within the vessel as this can significantly impact the implantation and performance of a scaffold. The study investigated mechanics of stent-vessel interaction, comparing the performance of polymeric and metallic stents with consideration of eccentric and concentric shapes of the arterial plaque. It was shown that polymeric scaffolds generated lower stresses in the vessel wall, and recoiled further after expansion than their metallic counterparts. The study illustrated that eccentric plaque retained high stresses in different layers of the artery. Eccentricity caused uneven radial expansion, affecting the scaffold performance. Simulating performance of scaffolds in vessels with atherosclerotic lesions could enable assessment of mechanical behaviour of different stent designs with various plaque compositions, offering a best fit for a patient-specific plaque.

\section{Conclusion}

Due to the increasing prevalence of bioresorbable PLLA scaffolds, specifically stents in the medical-devices field, there is a need to understand and quantify the mechanical response of these scaffolds to in-service conditions prior to their implant together with associated changes in this response during their degradation. This knowledge will allow engineers to enhance the development and design optimization of stents in order to improve their performance. Issues, arising from use of metal stents, can be relieved with the use of polymer scaffolds, presenting many benefits compared to permanent stenting, including restoration of vasomotion. Degradation profiles of polymer scaffolds are controlled by multiple factors including molecular weight, degree of crystallinity as well as loads applied to the structure. Experimental quantification of the non-linear mechanical response for the viscoelastic polymer enables validation of computational (FE) models, with numerical simulations permitting predictions of in-vivo behaviour of scaffolds. This review highlighted recent progression in material models and FE simulations endorsed by experimental testing. Still, it is apparent that further experimental and computational studies are required to understand specific features of mechanical behaviour of PLLA scaffolds, including their performance prior to, and during, degradation. Additionally, developing specific material models for each type of PLLA stent due to the different manufacturing procedures and compositions is necessary because of varying performance of different PLLA stents. Achieving this will enable improvement and enhancement of future generations of polymer scaffolds with improved prediction of their mechanical performance, allowing enhancement of medical procedures and accelerated healing of patients.

\section{Abbreviations}

ASTM: American Society for testing and Materials; BMS: Bare metal stents; BRS: Bioresorbable scaffolds; CABG: Coronary artery bypass grafting; CHD: Coronary heart disease; DES: Drug eluting stents; FDA: Food and Drug administration; NHS: National Health Service; PCl: Percutaneous coronary intervention; PLLA: Poly-L-Lactic acid

\section{Funding}

RN is funded by the British Heart Foundation for her PhD research project (Grant number: FS/15/21/31424; Title: Towards controlling the mechanical performance of polymeric bioresorbable vascular scaffold during biodegradation)

\section{Authors' contributions}

RN carried out the literature review and wrote the paper; $L G Z, Y L$ and WS edited the paper. All authors read and approved the final manuscript.

\section{Authors' information}

RN is a PhD student, LGZ is a professor in Solid Mechanics, YL is a Senior Lecturer of Healthcare Engineering and WS is a professor in Mechanics of Materials. All work at Wolfson School of Mechanical, Electrical and Manufacturing Engineering, Loughborough University of the UK.

Consent for publication

All authors agree to publications.

Competing interests

The authors declare that they have no competing interests.

\section{Publisher's Note}

Springer Nature remains neutral with regard to jurisdictional claims in published maps and institutional affiliations.

Received: 26 May 2017 Accepted: 10 July 2017

Published online: 25 July 2017

\section{References}

Abbott Absorb and Absorb GT1 - Bioresorbable Vascular Scaffold Systems. https:// www.vascular.abbott/int/products/coronary-intervention/absorb-bioresorbablescaffold-dissolving-stent.html. Accessed 1 Oct 2016

Abizaid A, Costa JR Jr. (2010) New drug-eluting stents: an overview on biodegradable and polymer-free next-generation stent systems. Circ Cardiovasc Interv 8:384-393

Agrawal CM, Haas KF, Leopold DA, Clark HG (1992) Evaluation of poly(L-lactic acid) as a material for intravascular polymeric stents. Biomater 13:176-182 http://dx.doi.org/10.1016/0142-9612(92)90068-Y

ASTM (2014a) Standard guide for three-point bending of balloon expandable vascular stents and stent systems

ASTM (2013) Standard guide for testing absorbable stents

Athanasiou KA, Agrawal CM, Barber FA, Burkhart SS (1998) Orthopaedic applications for PLA-PGA biodegradable polymers. Arthroscopy 14:726-737

Babuška I (1991) Mathematical models and engineering decisions. In: Finite Element Analysis. A Wiley-Interscience Publication, John Wiley \& Sons, Inc., New York/ Chichester/Brisbane/Toronto/Singapore 
Bardenhagen SG, Stout MG, Gray GT (1997) Three-dimensional, finite deformation, viscoplastic constitutive models for polymeric materials. Mech Mater 25:235-253

Bartkowiak-Jowsa M, Będziński R, Kozłowska A et al. (2012) Mechanical, rheological, fatigue, and degradation behavior of PLLA, PGLA and PDGLA as materials for vascular implants. Meccanica 48:721-731. doi:10.1007/s11012-012-9626-2

Bergstrom JS, Hayman D (2016) An overview of mechanical properties and material modeling of polylactide (PLA) for medical applications. Ann Biomed Eng 44:330-340. doi:10.1007/s10439-015-1455-8

Bobel AC, Lohfeld S, Shirazi RN, McHugh PE (2016) Experimental mechanical testing of poly (I-Lactide) (PLLA) to facilitate pre-degradation characteristics for application in cardiovascular stenting. Polym test 54:150-158 http://dx. doi.org/10.1016/j.polymertesting.2016.07.011

Bobel AC, Petisco S, Sarasua JR et al. (2015) Computational bench testing to evaluate the short-term mechanical performance of a polymeric stent. Cardiovasc Eng Technol 6:519-532

Bourantas CV, Onuma Y, Farooq V et al. (2013) Bioresorbable scaffolds: current knowledge, potentialities and limitations experienced during their first clinical applications. Int J Cardiol 167:11-21 http://dx.doi.org/10.1016/j.jjcard.2012.05.093

British Heart Foundation (2015) BHF Headline Statistics https://www.bhf.org.uk/ research/heart-statistics

Brugaletta S, Gogas BD, Garcia-Garcia HM et al. (2012) Vascular compliance changes of the coronary vessel wall after bioresorbable vascular scaffold implantation in the treated and adjacent segments. Circ J 76:1616-1623

Celermajer DS (1997) Endothelial dysfunction: does it matter? Is it reversible? J am Coll Cardiol 30:325-333 http://dx.doi.org/10.1016/S0735-1097(97)00189-7

Deroiné M, Le Duigou A, Corre Y-M et al. (2014) Accelerated ageing and lifetime prediction of poly(3-hydroxybutyrate-co- 3-hydroxyvalerate) in distilled water. Polym Test 39:70-78. doi:10.1016/j.polymertesting.2014.07.018

Dreher ML, Nagaraja S, Batchelor B (2016) Effects of fatigue on the chemical and mechanical degradation of model stent sub-units. J Mech Behav biomed mater 59:139-145 http://dx.doi.org/10.1016/j.jmbbm.2015.12.020

Dreher ML, Nagaraja S, Lu Q, et al. (2015) Degradation of PLLA tubes in a pulsatile flow loop as a model for cardiovascular stent degradation

Engels TAP, Söntjens SHM, Smit TH, Govaert LE (2009) Time-dependent failure of amorphous polylactides in static loading conditions. doi:10.1007/s10856-009-3851-9

Eswaran SK, Kelley JA, Bergstrom JS, Giddings VL (2011) Material modeling of Polylactide

Fambri L, Pegoretti A, Fenner R et al. (1997) Biodegradable fibres of poly(I-lactic acid) produced by melt spinning. Polymer (Guildf) 38:79-85. doi:10.1016/S00323861(96)00486-7

Ferdous J, Kolachalama VB, Kolandaivelu K, Shazly T (2015) Degree of bioresorbable vascular scaffold expansion modulates loss of essential function. Acta Biomater 26:195-204. doi:10.1016/j.actbio.2015.08.009

Foin N, Lee R, Mattesini A et al. (2016) Bioabsorbable vascular scaffold overexpansion: insights from in vitro post-expansion experiments. Eurolntervention 11:1389-1399. doi:10.4244/EIJY15M07_02

Foin N, Lee RD, Torii R et al. (2014) Impact of stent strut design in metallic stents and biodegradable scaffolds. Int J Cardiol 177:800-808 http://dx.doi.org/10. 1016/j.jijcard.2014.09.143

Fortier A, Gullapalli V, Mirshams RA (2014) Review of biomechanical studies of arteries and their effect on stent performance. IJC hear vessel 4:12-18 http://dx.doi.org/10.1016/j.ijchv.2014.04.007

Gada H, Kirtane AJ, Newman W et al. (2013) 5-year results of a randomized comparison of XIENCE $V$ everolimus-eluting and TAXUS paclitaxel-eluting stents: final results from the SPIRIT III trial clinical evaluation of the XIENCE V everolimus eluting coronary stent system in the treatment of patient. JACC Cardiovasc Interv 6:1263-1266. doi:10.1016/j.jcin.2013.07.009

Gomez-Lara J, Brugaletta S, Farooq V et al. (2011) Angiographic geometric changes of the lumen arterial wall after bioresorbable vascular scaffolds and metallic platform stents at 1-year follow-up. JACC Cardiovasc Interv 4:789-799 http://dx.doi.org/10.1016/j.jcin.2011.04.009

Gomez-Lara J, Garcia-Garcia HM, Onuma Y et al. (2010) A comparison of the conformability of everolimus-eluting bioresorbable vascular scaffolds to metal platform coronary stents. JACC Cardiovasc Interv 3:1190-1198 http://dx.doi.org/10.1016/j.jcin.2010.07.016

Gong Y, Zhou Q, Gao C, Shen J (2007) In vitro and in vivo degradability and cytocompatibility of poly(l-lactic acid) scaffold fabricated by a gelatin particle leaching method. Acta biomater 3:531-540 http://dx.doi.org/10.1016/.actbio.2006.12.008

Göpferich A (1996) Mechanisms of polymer degradation and erosion. Polym scaffolding hard tissue Eng 17:103-114. doi: http://dx.doi.org/10.1016/01429612(96)85755-3
Grabow N, Schlun M, Sternberg K et al. (2005) Mechanical roperties of laser cut poly(L-lactide) micro-specimens: implications for stent design, manufacture, and sterilization. J Biomech Eng 127:25-31. doi:10.1115/1.1835349

Grijpma DW, Altpeter H, Bevis MJ, Feijen J (2002) Improvement of the mechanical properties of poly(D,L-lactide) by orientation. Polym Int 51: 845-851. doi:10.1002/pi.988

Gruntzig A (1978) Transluminal dilatation of coronary-artery stenosis. Lancet (London, England) 1, 263

Gupta B, Revagade N, Hilborn J (2007) Poly(lactic acid) fiber: an overview. Prog Polym Sci 32:455-482. doi:10.1016/j.progpolymsci.2007.01.005

Hara H, Nakamura M, Palmaz JC, Schwartz RS (2006) Role of stent design and coatings on restenosis and thrombosis. Drug-eluting stents an Innov Multidiscip drug Deliv Platf 58:377-386 http://dx.doi.org/10.1016/j.addr.2006.01.022

Hayman D, Bergerson C, Miller S et al. (2014) The effect of static and dynamic loading on degradation of PLLA stent fibers. J Biomech Eng 6: 81006-81006-81006-81009

Hermawan H, Dubé D, Mantovani D (2010) Developments in metallic biodegradable stents 2 ‘. Acta Biomater 6:1693-1697. doi:10.1016/j.actbio.2009.10.006

Hoffmann R, Mintz GS (2000) Coronary in-stent restenosis - predictors, treatment and prevention. Eur Heart J 21:1739-1749. doi:10.1053/euhj.2000.2153

lakovou I, Schmidt T, Bonizzoni E et al. (2005) Incidence, predictors, and outcome of thrombosis after successful implantation of drug-eluting stents. JAMA 293: 2126-2130. doi:10.1001/jama.293.17.2126

lqbal J, Onuma Y, Ormiston J et al. (2014) Bioresorbable scaffolds: rationale, current status, challenges, and future. Eur Heart J 35:765-776. doi:10.1093/eurheartj/eht542

Khan KA, El-Sayed T (2013) A phenomenological constitutive model for the nonlinear viscoelastic responses of biodegradable polymers. Acta Mech 224: 287-305. doi:10.1007/s00707-012-0760-7

Kimble LD, Bhattacharyya D (2015) In Vitro degradation effects on strength, stiffness, and creep of PLLA/PBS: a potential stent material. Int J Polym Mater Polym Biomater 64:299-310. doi:10.1080/00914037.2014.945203

Kočka V, Toušek P, Widimský P (2015) Absorb bioresorbable stents for the treatment of coronary artery disease. Expert Rev Med Devices 12:545-557. doi:10.1586/17434440.2015.1080119

Kossuth MB, Perkins LEL, Rapoza RJ (2017) Design principles of bioresorbable polymeric scaffolds. Interv Cardiol Clin 5:349-355 http://dx.doi.org/10.1016/j. iccl.2016.02.004

Kristensen SD, Grove E (2007) Stent thrombosis: Definitions, Mechanisms and Prevention http://www.escardio.org/Guidelines-\&-Education/Journals-andpublications/ESC-journals-family/E-journal-of-Cardiology-PracticeNolume-5/ Stent-thrombosis-definitions-mechanisms-and-prevention-Title-Stent-thrombos

Lanzer P, Schmidt W (2015) Instrumentation for coronary artery interventions. In: Lanzer P (ed) PanVascular Medicine. Springer Berlin Heidelberg, Berlin, Heidelberg, pp 1979-2027

Leenslag JW, Gogolewski S, Pennings AJ (1984) Resorbable materials of poly(L-lactide). V. Influence of secondary structure on the mechanical properties and hydrolyzability of poly(L-lactide) fibers produced by a dryspinning method. J Appl Polym Sci 29:2829-2842. doi:10.1002/app.1984. 070290913

LeGrand DG (2011) Annealing. In: In: Encyclopedia of Polymer Science and Technology

Li S, Vert M (2002) Biodegradation of aliphatic polyesters. In: Degradable Polymers. Springer Netherlands, Dordrecht, pp 71-131

Luo Q, Liu X, Li Z et al. (2014) Degradation model of bioabsorbable cardiovascular stents. PLoS One 9:e110278. doi:10.1371/journal.pone.0110278

Madhavan Nampoothiri K, Nair NR, John RP (2010) An overview of the recent developments in polylactide (PLA) research. Bioresour Technol 101:84938501. doi:10.1016/j.biortech.2010.05.092

Meijer HEH, Govaert LE (2005) Mechanical performance of polymer systems: the relation between structure and properties. Prog Polym Sci 30:915-938. doi:10.1016/j.progpolymsci.2005.06.009

Middleton JC, Tipton AJ (2000) Synthetic biodegradable polymers as orthopedic devices. Biomaterials 21:2335-2346

Muliana A, Rajagopal KR (2012) Modeling the response of nonlinear viscoelastic biodegradable polymeric stents. Int J solids Struct 49:989-1000 http://dx.doi. org/10.1016/j.ijsolstr.2011.12.007

Nerkar M, Ramsay JA, Ramsay BA, Kontopoulou M (2014) Dramatic improvements in strain hardening and crystallization kinetics of PLA by simple reactive modification in the melt state. Macromol Mater Eng 299:1419-1424. doi:10.1002/mame.201400078

NHS (2014) Cardiovascular Disease http://www.nhs.uk/conditions/cardiovasculardisease/pages/introduction.aspx. Accessed 1 Mar 2017 
$\mathrm{NIH}$ (2012) What is coronary artery bypass grafting? http://www.nhlbi.nih.gov/ health/health-topics/topics/cabg. Accessed 1 Mar 2017

Nishio S, Kosuga KFAU, Igaki KFAU et al. (2012) Long-term (>10 years) clinical outcomes of first-in-human biodegradable poly-l-lactic acid coronary stents: Igaki-Tamai stents. Circulation 125:2343-2353

O' Brien ER, Ma X, Simard T et al. (2011) Pathogenesis of neointima formation following vascular injury. Cardiovasc Hematol Disord Drug Targets 11:30-39

Oberhauser J, Hossainy S, Rapoza R (2009) Design principles and performance of bioresorbable polymeric vascular scaffolds. Eurolntervention 5:F15-F22

Ormiston JA, Serruys PW, Regar E, et al. (2008) A bioabsorbable everolimuseluting coronary stent system for patients with single de-novo coronary artery lesions (ABSORB): a prospective open-label trial. Lancet 371:899-907. doi: http://dx.doi.org/10.1016/S0140-6736(08)60415-8

Ormiston JA, Serruys PWS (2009) Bioabsorbable coronary stents. Circ Cardiovasc Interv 2:255-260

Ormiston JA, Webster MWI, Armstrong G (2007) First-in-human implantation of a fully bioabsorbable drug-eluting stent: the BVS poly-L-lactic acid everolimuseluting coronary stent. Catheter Cardiovasc Interv 69:128-131

Pan J (2015) Modelling degradation of semi-crystalline biodegradable polyesters. In: Pan J (ed) Modelling degradation of Bioresorbable polymeric medical devices. Woodhead publishing, Elsevier, pp 53-69

Pauck RG, Reddy BD (2015) Computational analysis of the radial mechanical performance of PLLA coronary artery stents. Med Eng Phys 37:7-12 http://dx. doi.org/10.1016/j.medengphy.2014.09.014

Perego G, Cella GD, Bastioli C (1996) Effect of molecular weight and crystallinity on poly(lactic acid) mechanical properties. J Appl Polym Sci 59:37-43. doi:10.1002/(SICI)1097-4628(19960103)59:1<37::AID-APP6>3.0.CO;2-N

Pham T, Deherrera M, Sun W (2014) Finite element analysis of the biomechanical interaction between coronary sinus and proximal anchoring stent in coronary sinus annuloplasty. Comput Methods Biomech Biomed Engin 17: 1617-1629. doi:10.1080/10255842.2012.758719

Pruitt LA, Chakravartula AM (2011) Mechanics of biomaterials: fundamental principles for implant design. Cambridge University Press, Cambridge

Quynh TM, Mitomo H, Nagasawa N et al. (2007) Properties of crosslinked polylactides (PLLA \& PDLA) by radiation and its biodegradability. Eur Polym J 43 1779-1785 http://dx.doi.org/10.1016/j.eurpolymj.2007.03.007

Renouf-Glauser AC, Rose J, Farrar DF, Cameron RE (2005) The effect of crystallinity on the deformation mechanism and bulk mechanical properties of PLLA Biomater 26:5771-5782 http://dx.doi.org/10.1016/j.biomaterials.2005.03.002

Röhm E, Aldrich S RESOMER ${ }^{\circledR}$ Biodegradable polymers for medical device applications. http://www.sigmaaldrich.com/materials-science/polymer-science/resomer.html\#a4

Rosa S, Caoimhe S, Nicola K, Peter M (2016) Finite element analysis of bioresorbable polymers using a thermo-mechanical co-simulation model. In: In: Frontiers in Bioengineering and Biotechnology

Sarasua JR, Arraiza AL, Balerdi P, Maiza I (2005) Crystallinity and mechanical properties of optically pure polylactides and their blends. Polym Eng Sci 45: 745-753. doi:10.1002/pen.20331

Schatz RA, Goldberg S, Leon M et al. (1991) Clinical experience with the PalmazSchatz coronary stent. J Am Coll Cardiol 17:155-159

Schiavone A, Abunassar C, Hossainy S, Zhao LG (2016) Computational analysis of mechanical stress-strain interaction of a bioresorbable scaffold with blood vessel. J Biomech 49:2677-2683 http://dx.doi.org/10.1016/j.jbiomech.2016.05.035

Schiavone A, Qiu T, Zhao L (2017) Crimping and deployment of metallic and polymeric stents - finite element modelling. Vessel Plus 1:12-21

Schiavone A, Zhao LG (2016) A computational study of stent performance by considering vessel anisotropy and residual stresses. Mater Sci Eng C 62:307-316 http://dx.doi.org/10.1016/.j.msec.2016.01.064

Schmidt W, Behrens P, Brandt-Wunderlich C et al. (2016) In vitro performance investigation of bioresorbable scaffolds - standard tests for vascular stents and beyond. Cardiovasc Revasc Med. doi:10.1016/j.carrev.2016.05.001

Serruys PW, de Jaegere P, Kiemeneij F et al. (1994) A omparison of balloonexpandable-stent implantation with balloon angioplasty in patients with coronary artery disease. N Engl J Med 331:489-495. doi:10.1056/NEJM199408253310801

Serruys PW, FAU OJA, Onuma YFAU, et al. (2009) A bioabsorbable everolimuseluting coronary stent system (ABSORB): 2-year outcomes and results from multiple imaging methods. Lancet (London, England) JID - 2985213R

Serruys PW, Garcia-Garcia HM, Onuma Y (2012) From metallic cages to transient bioresorbable scaffolds: change in paradigm of coronary revascularization in the upcoming decade? Eur Heart J 33:16-25. doi:10.1093/eurheartj/ehr384

Serruys PW, Kutryk MJB, Ong ATL (2006) Coronary-artery stents. N Engl J Med 354:483-495
Simard T, Hibbert B, Ramirez FD et al. (2014) The evolution of coronary stents: a brief review. Can J Cardiol 30:35-45 http://dx.doi.org/10.1016/j.cjca.2013.09.012

Sin LT, Rahmat AR, Rahman WAWA (2012) Polylactic acid: PLA biopolymer technology and applications. William Andrew

Soares JS, Moore JE, Rajagopal KR (2010a) Modeling of deformation-accelerated breakdown of polylactic acid biodegradable stents. J Med Device 4:41007. doi:10.1115/1.4002759

Soares JS, Moore JE, Rajagopal KR (2008) Constitutive framework for biodegradable polymers with applications to biodegradable stents. ASAIO J 54:295-301

Soares JS, Rajagopal KR, Moore JE (2010b) Deformation-induced hydrolysis of a degradable polymeric cylindrical annulus. Biomech Model Mechanobiol 9: 177-186. doi:10.1007/s10237-009-0168-z

Söntjens SHM, Engels TAP, Smit TH, Govaert LE (2012) Time-dependent failure of amorphous poly-d,I-lactide: Influence of molecular weight. J Mech Behav Biomed Mater 13:69-77. doi:10.1016/j.jmbbm.2012.04.014

Tamai H, Igaki K, Kyo E et al. (2000) Initial and 6-month results of biodegradable poly-l-lactic acid coronary stents in humans. Circulation 102:399-404

Verheye S, Ormiston JA, Stewart J et al. (2014) A next-generation bioresorbable coronary scaffold system: from bench to first clinical evaluation. JACC Cardiovasc Interv 7:89-99

Vieira AC, Guedes RM, Tita V (2015) On different approaches to simulate the mechanical behavior of scaffolds during degradation. Procedia Eng 110:21-28. doi:10.1016/j.proeng.2015.07.005

Wang L, Ma W, Gross RA, McCarthy SP (1998) Reactive compatibilization of biodegradable blends of poly(lactic acid) and poly( $\varepsilon$-caprolactone). Polym Degrad Stab 59:161-168. doi:10.1016/S0141-3910(97)00196-1

Wang Q, Fang G, Zhao Y et al. (2017) Computational and experimental investigation into mechanical performances of poly-L-Lactide acid (PLLA) coronary stents. J Mech Behav biomed mater 65:415-427 http://dx.doi.org/ 10.1016/j.jmbbm.2016.08.033

Wang Y (2013) Bioabsorbable scaffolds made from composites. US patent Appl $13 / 107,643$

Weir NA, Buchanan FJ, Orr JF et al. (2004) Processing, annealing and sterilisation of polyHactide. Biomater 25:3939-3949 http://dx.doi.org/10.1016/j.biomaterials.2003.10.076

Welch TR, Eberhart RC, Chuong C-J (2008) The influence of thermal treatment on the mechanical characteristics of a PLLA coiled stent. J Biomed Mater Res Part B Appl Biomater 90B:302-311

Widmer RJ, Lerman LO, Lerman A et al. (2016) MicroRNAs: small molecule, big potential for coronary artery disease. Eur Heart J 37:1750-1752. doi:10.1093/ eurheartj/ehw067

Yang K, Fernandez N (2015) Method for fabricating medical devices with porous polymeric structures

Yuan X, Mak AFT, Yao K (2002) Comparative observation of accelerated degradation of poly(l-lactic acid) fibres in phosphate buffered saline and a dilute alkaline solution. Polym Degrad stab 75:45-53 http://dx.doi.org/10. 1016/S0141-3910(01)00203-8

Zhang C (2015) Biodegradable polyesters: synthesis, properties, applications. In: Biodegradable Polyesters. Wiley-VCH Verlag GmbH \& Co, KGaA, pp 1-24

Zilberman M, FAU NKD, Eberhart RC (2005) Mechanical properties and in vitro degradation of bioresorbable fibers and expandable fiber-based stents. J Biomed Mater Res Part B Appl Biomater 74B:792-799

Zilberman M, Schwade ND, Eberhart RC (2004) Protein-loaded bioresorbable fibers and expandable stents: mechanical properties and protein release. J Biomed Mater Res 69B:1-10. doi:10.1002/jbm.b.20026

\section{Submit your manuscript to a SpringerOpen ${ }^{\circ}$ journal and benefit from:}

- Convenient online submission

- Rigorous peer review

- Open access: articles freely available online

- High visibility within the field

Retaining the copyright to your article

Submit your next manuscript at $>$ springeropen.com 